\title{
A ARQUEOLOGIA DA DIÁSPORA AFRICANA NOS ESTADOS UNIDOS E NO BRASIL: PROBLEMÁTICAS E MODELOS
}

\section{Luís Cláudio P. Symanski*}

$\mathrm{E}$ ste artigo tem por meta realizar uma revisão da literatura sobre a arqueologia da diáspora africana nos Estados Unidos e no Brasil, focalizando os principais temas estudados e os modelos teóricos que têm sido empregados para entender a dinâmica social das populações africanas na diáspora sob o viés da cultura material presente nos sítios históricos. O grande volume de pesquisas realizadas nos Estados Unidos desde o início da década de 1970, em contextos como senzalas de plantations, sítios rurais do período pós-emancipatório, quilombos, unidades domésticas urbanas, cemitérios urbanos e rurais dentre outros, não permite uma revisão exaustiva do tema, de modo que áreas que têm tido um significativo desenvolvimento, como a arqueologia mortuária, não foram aqui contempladas. No Brasil, por outro lado, as pesquisas são ainda raras, embora tenham se acentuado ao longo da última década, o que inviabiliza uma abordagem orientada para o desenvolvimento e as

\footnotetext{
* Professor da Universidade Federal de Minas Gerais. symanski@ufl.edu. Uma primeira versão, não publicada, deste trabalho foi elaborada no período em que eu cursava o doutorado na Universidade da Flórida, como produto de cursos e estudos individuais realizados com Kathleen Deagan e James Davidson. Sou grato a ambos pelas discussões, ensinamentos e co-orientação no desenvolvimento da minha tese. Agradeço a Marcos André Torres de Souza pela leitura atenta, comentários e sugestões, além das muitas discussões e trocas sobre arqueologia histórica e diáspora africana. Por fim, agradeço as considerações de um revisor anônimo. Destaco que qualquer erro ou interpretação errônea no conteúdo deste artigo é de minha exclusiva responsabilidade.
} 
mudanças de perspectivas teóricas. Não obstante, escavações realizadas em quilombos e senzalas em algumas regiões do Brasil têm permitido um conhecimento mais aprofundado das condições materiais de vida de grupos escravizados e da sua capacidade de agência frente às limitações impostas pelo sistema escravista.

\section{A arqueologia da diáspora africana nos Estados Unidos}

A primeira pesquisa sobre um sítio afro-americano foi realizada no início da década de 1940, no quintal de uma habitação em Andover, Massachusetts, que havia sido ocupada entre 1815 e 1845 por Lucy Foster, uma liberta. Trata-se de um trabalho descritivo, cujo propósito principal foi estabelecer relação entre os documentos sobre o sítio e os vestígios materiais exumados, para verificar se o período de produção destes últimos coincidiria com o documentado período de ocupação. Não houve interesse em correlacionar o material a comportamentos e práticas dos ocupantes do sítio, sendo apenas notificado, na parte final do artigo, que a história do sítio consistia "na biografia de Lucy Foster, uma negra", fazendo-se necessário fornecer algumas informações sobre sua trajetória de vida. ${ }^{1}$

Pesquisas sistemáticas em sítios afro-americanos começaram somente no início da década de 1970, com o trabalho de Fairbanks e sua equipe em senzalas de plantations da Flórida e da Geórgia. ${ }^{2}$ Como a maioria dos estudiosos da cultura afro-americana daquele período, Fairbanks seguiu a agenda proposta décadas antes por Herskovits, ${ }^{3}$ que elaborou um modelo de sobrevivência e aculturação africana no Novo Mundo e cunhou o termo africanismo para referir-se às práticas e costumes de origem africana. Herskovits considerava que as regiões da

\footnotetext{
1 Adelaide Bullen e Ripley Bullen, "Black Lucy’s Garden”, Bulletin of the Massachusetts Archaeological Society, v. 5, n. 2 (1944), pp. 20-5.

2 Charles Fairbanks, "The Kingsley Slave Cabins in Duval County, Florida, 1968”, The Conference on Historic Site Archaeology Papers, v. 7 (1972), p. 62-93; Charles Fairbanks, "The Plantation Archaeology of Southeastern Coast", Historical Archaeology, v. 28, n. 1 (1984), pp. 41-64; Robert Ascher e Charles Fairbanks, "Excavation of a Slave Cabin: Georgia, USA", Historical Archaeology, v. 5 (1971), pp. 3-17;

Melville Herskovits, The Myth of the Negro Past, Boston: Beacon Press, 1941.
} 
África Ocidental e Central, de onde saiu a enorme maioria dos africanos, compunham uma única grande área cultural, ${ }^{4} \mathrm{o}$ que teria resultado em um alto nível de homogeneidade cultural das populações escravizadas nas Américas - ideia rejeitada pelos estudiosos atuais -, sendo a cultura afro-americana um produto direto da herança africana. Procurando investigar o processo de emergência dessa cultura, Fairbanks buscava seus restos tangíveis no registro arqueológico, porém seu insucesso em encontrar tais vestígios levou-o a considerar que a repressão sistemática dos proprietários sobre as manifestações culturais dos cativos teria levado à erosão dessa matriz africana. ${ }^{5}$ Desse modo, Fairbanks e seus discípulos abandonaram a busca de possíveis africanismos na cultura material, voltando-se para o estudo das condições materiais de vida desses grupos nas plantations, como será apresentado adiante. ${ }^{6}$

As ideias de Herskovits enquadravam-se em um modelo de aculturação que vinha sendo desenvolvido na antropologia norte-americana desde a década de 1920, com Franz Boas, para quem o estudo desse fenômeno forneceria a única via de acesso para o entendimento das forças internas da dinâmica cultural. ${ }^{7}$ Nas décadas seguintes, a aculturação tornou-se um dos temas centrais da antropologia norte-americana, merecendo a publicação de um memorando dedicado ao seu estudo nas revistas Man de 1935 e American Anthropologist de $1936 .{ }^{8}$ Dentre os aspectos comuns a tais estudos, destacam-se a listagem dos traços culturais transmitidos entre as sociedades, a visão de culturas como entidades bem delimitadas, a minimização da agência humana, a identificação dos mecanismos de filtragem que explicariam a incorporação seletiva de traços da cultura forânea e a omissão das relações de poder,

Herskovits, The Myth, p. 295.

Fairbanks, "The Plantation Archaeology", p. 10.

Ver exemplos em Fairbanks, "The Kingsley Slave Cabins; Sue Moore, "Social and Economic Status on the Coastal Plantation: an Archaeological Perspective", in Thereza Singleton (org.), The Archaeology of Slavery and Plantation Life (San Diego: Academic Press, 1985), pp. 141-61; John Otto, Cannon's Point Plantation, 1794-1860: Living Conditions and Status Patterns in the Old South, Orlando/San Diego/San Francisco/New York: Academic Press, 1984.

7 Franz Boas, Antropologia cultural, Rio de Janeiro: Zahar, 2004, p. 46.

8 Ver James Cusick, "Historiography of Acculturation: an Evaluation of Concepts and Their Application in Archaeology", in James Cusick (org.), Studies in Culture Contact: Interaction, Culture Change, and Archaeology (Carbondale: Center for Archaeological Investigations, 1998), pp. 126-45. 
com tendência a considerar que as sociedades mais simples incorporariam passivamente os traços da cultura dominante. ${ }^{9}$ Os pressupostos de Fairbanks enquadravam-se, portanto, no modelo de aculturação, não somente em sua busca por uma cultura matriz africana pura no registro arqueológico mas também em sua justificativa para a suposta ausência dos africanismos, que evidenciaria a adoção da cultura anglo-americana dominante, imposta à população afro-americana por meio da repressão.

A temática da aculturação continuou em pauta na arqueologia afro-americana até os anos 1980, como exemplifica o trabalho de Wheaton e Garrow sobre duas plantations da Carolina do Sul, ocupadas entre 1740 e o início do século XIX, que aponta mudanças na arquitetura doméstica, na cerâmica artesanal (chamada colonoware) e padronização dos artefatos provenientes das senzalas. Os autores constataram a evolução das habitações dos cativos de cabanas de pau a pique de estilo africano ocidental para construções de estilo arquitetônico euro-americano, a redução da frequência de colonoware e o aumento concomitante de uso das louças europeias e de outras categorias de artefatos industrializados. Tais mudanças indicariam uma maior conformação da cultura de matriz africana desses grupos aos modelos culturais euro-americanos, como consequência da crescente presença euro-americana na região depois da Guerra de Independência Americana (1775-1783), que teria diminuído o isolamento dos cativos. ${ }^{10}$

Em adição aos problemas enumerados por Cusick, ${ }^{11}$ o emprego do modelo de aculturação em arqueologia pautou-se em uma premissa comum aos estudos histórico-culturalistas, que vem sendo questionada desde o advento da Nova Arqueologia, ${ }^{12}$ na década de 1960: a igualiza-

\footnotetext{
Cusick, "Historiography of Acculturation", p. 131.

10 Thomas Wheaton e Patrick Garrow, "Acculturation and the Archaeological Record in Carolina Lowcountry”, in Singleton (org.), The Archaeology of Slavery, pp. 239-59.

1 Cusick, "Historiography of Acculturation, p. 131.

12 A Nova Arqueologia ou Arqueologia Processual foi um movimento que se iniciou nos Estados Unidos, na década de 1960, encabeçado por Lewis Binford, que defendia uma perspectiva científica, positivista, materialista e sistêmica para a arqueologia, rejeitando os pressupostos histórico-culturalistas da antropologia boasiana em favor de uma arqueologia antropológica pautada na ecologia cultural e no neoevolucionismo de Leslie White e Julian Steward. Ver Bruce Trigger, A History of Archaeological Thought, Cambridge: Cambridge University Press, 1989, pp. 289-328.
} 
ção de artefatos e/ou conjuntos de artefatos com culturas, as chamadas "culturas arqueológicas". ${ }^{13}$ Essa premissa fundamenta-se em uma concepção essencialista de etnicidade segundo a qual um grupo étnico é caracterizado com base em uma listagem de traços culturais que lhe são específicos, os quais devem apresentar correlatos no registro material, como subentende a própria noção de africanismo. Assim, espera-se que o registro arqueológico apresente elementos diagnósticos de grupos étnicos específicos, evidenciados a partir de tradições estilísticas ou de padrões de artefatos. ${ }^{14}$ Como resultado, a ausência, no registro arqueológico, de elementos materiais característicos da cultura afro-americana é interpretada como uma evidência direta de aculturação, na qual a tradição cultural afro-americana teria sido "apagada" pelo uso dos objetos euro-americanos. ${ }^{15}$

Por fim, os estudos de aculturação podem ainda ser criticados como abordagens exclusivamente éticas, no sentido de pautadas nos sistemas de valores dos grupos dominantes, ignorando-se os modos específicos a partir dos quais os grupos escravizados poderiam se reapropriar da cultura material euro-americana com base nos seus próprios referenciais culturais. Desse modo, os cativos são considerados inaptos para se engajar em estratégias de negociação social, aceitando passivamente os estímulos da sociedade dominante.

Na década de 1970, a influência da nova arqueologia chegou à arqueologia histórica, inicialmente a partir dos trabalhos de South, ${ }^{16}$ que propôs que a arqueologia histórica focalizasse o comportamento humano e os processos culturais, o que envolveria, em primeira instância, o reconhecimento de padrões arqueológicos a partir de métodos quantitativos. Em consequência, as pesquisas arqueológicas em contextos afro-americanos começaram a buscar padrões típicos dessas populações,

\footnotetext{
13 Críticas à noção de cultura arqueológica são encontradas em Sian Jones, The Archaeology of Ethnicity: Constructing Identities in the Past and Present, London: Routledge, 1997; S. Shennan "Introduction", in S. Shennan (org.), Archaeological Approaches to Cultural Identity (London: Routledge, 1989), pp. 1-32; Trigger, A History, pp.148-206.

14 Jones, The Archaeology, pp. 106-10.

15 Thereza Singleton, "Cultural Interaction and African American Identity in Plantation Archaeology”, in Cusick (org.), Studies in Culture Contact, p. 176.

16 Stanley South, Method and Theory in Historical Archaeology, New York: Academic Press, 1977.
} 
que deveriam ser explicados em termos de comportamento culturalmente específico e de status socioeconômico. ${ }^{17}$

Retomando a análise das amostras do quintal de Lucy Foster e buscando identificar tais padrões, Baker ${ }^{18}$ verificou que a alta incidência de tigelas (41\%), a predominância total de restos faunísticos despedaçados e as dimensões das habitações (com 12 pés de comprimento por 12 pés de largura) apresentavam grande semelhança com as de outros sítios afro-americanos, como as senzalas da plantation Cannon's Point ${ }^{19} \mathrm{e} o$ assentamento de Parting Ways, ${ }^{20}$ sugerindo padrões de comportamento material que seriam caracteristicamente afro-americanos.

Otto, por sua vez, buscando contrastar o comportamento material dos cativos da plantation Cannon's Point com o dos brancos livres, ${ }^{21}$ identificou uma forte variabilidade intrassítio na arquitetura, na cerâmica e em restos faunísticos, relacionada com padrões específicos de três grupos sociais - escravos, capatazes e senhores - , padrões esses que remeteriam tanto aos comportamentos específicos de cada grupo quanto às distintas categorias de status típicas da sociedade do sul escravista: racial/legal, social e elite/subordinado. Os cativos viviam em habitações com dimensões de 12 x 12 pés, muito próximas das dimensões das habitações da África Ocidental (10 x 10 pés), preparavam suas refeições sob a forma de cozidos, quebravam os ossos para a extração do tutano e consumiam os alimentos predominantemente em tigelas de louça, sem decoração ou decoradas com faixas e frisos. Por outro lado, os proprietários consumiam carne assada, o que se evidenciava nas marcas de corte dos ossos, servida em pratos de louça fina decalcada. Os capatazes apresentavam um comportamento material ambíguo, um meio-termo entre os padrões dos proprietários e os dos cativos.

O reconhecimento de padrões arqueológicos e suas implicações

\footnotetext{
17 Ver, por exemplo, Vernon Baker, "Archaeological Visibility of Afro-American Culture: an Example from Black Lucy's Garden, Andover, Massachusetts", in Robert Schuyler (org.), Archaeological Perspectives on Ethnicity in America (New York: Baywood, 1980), pp. 29-37; Otto, Cannon's Point Plantation; Moore, "Social and Economic Status".

18 Baker, "Archaeological Visibility".

19 Otto, Cannon's Point Plantation.

20 James Deetz, In Small Things Forgotten, New York, Doubleday, 1996 [1977].

21 Otto, Cannon's Point Plantation. 
em termos de status socioeconômico foi também o foco da pesquisa de Moore, ${ }^{22}$ em que são comparadas amostras de três plantations da costa sudeste cujos proprietários apresentavam níveis de renda que variavam entre baixo, médio e alto. Também com vistas a identificar regularidades e diferenças no comportamento material de proprietários, capatazes e cativos, ela constatou, nas senzalas, uma predominância de louças decoradas com faixas, ao passo que as louças decalcadas seriam mais utilizadas nos contextos ocupados pelos proprietários. No entanto, sua análise não permitiu a identificação de padrões arqueológicos relacionados com status socioeconômico que pudessem ser claramente atribuídos a cada grupo social. Na plantation mais rica, os cativos dispuseram de louças de melhor qualidade do que na mais pobre, o que a levou a concluir que a riqueza do proprietário teria uma influência direta sobre os indicadores materiais de status socioeconômico nos contextos de senzala. Assim, nessas plantations, o status socioeconômico dos proprietários estaria indicado não somente por suas amostras mas também por aquelas de seus capatazes e cativos.

Ainda nos anos 1980, Adams e Boling empregaram a abordagem de reconhecimento de padrões socioeconômicos em um polêmico trabalho comparativo de amostras cerâmicas de três plantations da Geórgia, no qual apontaram alguns casos de senzalas com maior quantidade de porcelanas - o tipo de cerâmica de maior valor econômico — do que a registrada em algumas casas-grandes. ${ }^{23}$ Como, nas senzalas, os serviços de chá eram o tipo mais comum de porcelanas, eles levantaram a hipótese de que os cativos domésticos que viviam nessas senzalas teriam sido aculturados na cerimônia anglo-americana do chá e, assim, teriam adquirido serviços de chá para seu uso pessoal. Esse trabalho foi duramente criticado por Potter Jr., na medida em que os argumentos apresentados poderiam levar à minimização da crueldade da escravidão e, assim, negar a legitimidade dos apelos contra a discriminação racial da população afro-americana atual. ${ }^{24}$

Moore, "Social and Economic Status".

William Adams e Sarah Boling, "Status and Ceramics for Planters and Slaves on Three Georgia Coastal Plantations", Historical Archaeology, v. 23, n. 1 (1989), pp. 69-96.

24 Parker Potter Jr., "What Is the Use of Plantation Archaeology?", Historical Archaeology, v. 25, n. 3 (1991), pp. 94-107. 
É inegável que a abordagem de reconhecimento de padrões consistiu em um grande avanço, dado que o emprego de uma metodologia de análise uniforme permitiu comparações intra e intersítios e impulsionou os arqueólogos a refletir sobre a significância das variações do registro arqueológico em termos comportamentais, sociais e culturais. Porém, o reconhecimento e a explanação dos padrões arqueológicos levou a dois problemas de difícil resolução. O primeiro consiste na perspectiva totalmente ética dessa abordagem, fundamentada no funcionalismo e no formalismo econômico, que considera que os significados dos artefatos são somente atribuídos pela cultura hegemônica. Como, no caso dos estudos de aculturação, não se leva em conta a possibilidade de os grupos escravizados terem atribuído significados alternativos à cultura material presente em seus contextos de ocupação, eles são vistos como elementos passivos dentro do sistema, sem a mínima possibilidade de negociação social. O segundo problema diz respeito ao essencialismo típico dessa abordagem, uma vez que os grupos sociais são classificados de um modo estático e, consequentemente, enquadrados em um modelo comportamental congelado. A premissa subjacente é a de que existem padrões "puros", relacionados com a filiação social e cultural, porém passíveis de serem corrompidos por diferentes variáveis. Portanto, se algum indivíduo pertence a um grupo social específico, ele deverá manter o comportamento material característico desse grupo. O problema é que comportamentos mudam, não somente ao longo do tempo mas também em função de contextos e situações específicas, sendo influenciados por variáveis que, de tão diversificadas, não permitem identificação, mensuração e controle objetivos. Ao desconsiderar essa lógica situacional dos sujeitos, não raro tais estudos geraram discussões estéreis sobre até que ponto os inesperados "desvios do padrão" deveriam ser atribuídos a séries específicas de variáveis. Assim, a meta de muitas pesquisas tornou-se identificar tais variáveis para explicar por que as instâncias específicas não se enquadravam nos padrões esperados.

Em todo o caso, é importante reconhecer a validade da abordagem de reconhecimento de padrões como um método comparativo, tendo em vista que é a variabilidade artefatual no tempo e no espaço que permite à arqueologia estudar a dinâmica social do passado. É necessário, porém, 
que os padrões arqueológicos sejam avaliados em termos do contexto histórico e social de cada grupo em estudo, em vez de simplesmente com a meta de identificar regularidades relacionadas com a classe ou a etnicidade. O exemplo da predominância de tigelas em sítios de ocupação afro-americana é indicativo da aplicabilidade desse método. Há discussões sobre até que ponto esse padrão estaria relacionado com um comportamento étnico, de origem africana, ou derivaria de fatores socioeconômicos, mais especificamente de uma baixa condição econômica. ${ }^{25}$ O fato de DeCorse ter encontrado o mesmo padrão em sítios da África Ocidental do período colonial, que se manteve praticamente estável entre os séculos XVI e XIX, é altamente favorável à validade da primeira hipótese. ${ }^{26}$ Além disso, foi também encontrado um número significativo de tigelas nas senzalas dos engenhos da Chapada dos Guimarães, Mato Grosso, e nas de Goiás. ${ }^{27}$ Entretanto, mesmo que essa preferência tenha sido comum em tais contextos e, assim, indicativa de hábitos alimentares de origem africana centrados no consumo de alimentos ensopados, isso não significa que tenha sido uma norma geral e exclusiva desses grupos, pois o consumo de ensopados em tigelas foi comum a todos os segmentos socioculturais, de modo que as causas de sua predominância devem ser consideradas em função de cada contexto.

\section{A crítica marxista}

No começo da década de 1990, a arqueologia afro-americana entrou em uma fase mais autorreflexiva, quando arqueólogos adeptos de vertentes marxistas ${ }^{28}$ começaram a criticar as abordagens voltadas para a acultu-

25 Ver Charles Orser, "Race and the Archaeology of Identity in the New World", in Charles Orser (org.), Race and the Archaeology of Identity (Salt Lake City: The University of Utah Press, 2001), pp. 1-13; Moore, "Social and Economic Status", p. 149.

26 Christopher DeCorse, "Oceans Apart: Africanist Perspectives on Diaspora Archaeology", in Thereza Singleton (org.), "I, too, Am America”: Archaeological Studies of African-American Life (Charllottesville: University Press of Virginia, 1999), pp. 132-58.

27 Ver Luis Symanski, "Slaves and Planters in Western Brazil: Material Culture, Identity and Power" (Tese de Doutorado, University of Florida, 2006), p. 217; Marcos A. T. Souza, “A vida escrava portas adentro: uma incursão às senzalas do Engenho de São Joaquim, Goiás, século XIX”, Maracanan, v. 7 (2011), p. 83-109.

28 A arqueologia marxista norte-americana é representada principalmente por duas vertentes: a arqueologia crítica, com forte influência das concepções de Althusser e da teoria crítica da escola 
ração e o reconhecimento de padrões. ${ }^{29}$ Essas avaliações chamavam a atenção para o fato de que o simples compartilhamento de artefatos entre proprietários e cativos poderia envolver apenas um compartilhamento superficial de valores, uma vez que diferentes grupos podem atribuir significados distintos à mesma cultura material. Esses arqueólogos começaram, assim, a reconhecer o modelo de status como estático e descritivo e a chamar a atenção para o caráter dinâmico das relações de poder. ${ }^{30}$

$\mathrm{O}$ trabalho de Leone é pioneiro nessa abordagem. ${ }^{31}$ Fortemente influenciado pela tese da ideologia dominante de Althusser, Leone analisou as regras de perspectiva empregadas no jardim e na casa setecentista de William Paca, em Annapolis, para manipular a percepção, dando aos visitantes a impressão de estarem mais distantes da casa do que realmente se encontravam. Para o autor, esse artifício demonstrava o poder exercido pela elite sobre a natureza, servindo para naturalizar a arbitrariedade e as contradições de uma sociedade que proclamava a liberdade, ao mesmo tempo em que defendia a escravidão.

Seguindo essa perspectiva, Orser propôs que as plantations fossem analisadas como o domínio de poder dos proprietários, visto que eles estariam aptos a controlar a vida dos cativos por meio da distribuição de habitações, alimentos e artefatos. ${ }^{32}$ Potter Jr. defendeu basicamente essas mesmas ideias, afirmando que qualquer tipo de liberdade concedida a esses grupos era completamente monitorada; assim sendo, caberia aos arqueólogos estudar os modos pelos quais a cultura material havia sido empregada como um mecanismo de dominação. ${ }^{33}$

\footnotetext{
de Frankfurt; e a antropologia político-econômica, que enfatiza as lutas entre os membros da sociedade para o exercício do poder social. Ver Randall McGuire, "Archaeology and Marxism", Archaeological Method and Theory, v. 5 (1993), pp. 101-57; Robert Paynter e Randall McGuire, "The Archaeology of Inequality: an Introduction", in Randall McGuire e Robert Paynter (orgs.), The Archaeology of Inequality (Oxford: Basil, 1991), pp. 1-11.

29 Jean Howson, "Social Relations and Material Culture: a Critique of the Archaeology of Plantation Slavery", Historical Archaeology, v. 34, n. 2 (1990), pp. 78-91; Potter Jr., "What is the Use"; Brian Thomas, "Source Criticism and the Interpretation of African-American Sites", Southeastern Archaeology, v. 14, n. 2 (1995), pp. 149-57.

30 Howson, "Social relations", p. 78.

31 Mark Leone, "Interpreting Ideology in Historical Archaeology: Using the Rules of Perspective in the William Paca Garden in Annapolis, Maryland", in D. Miller e C. Tilley (orgs.), Ideology, Power and Prehistory (Cambridge: Cambridge University Press, 1984), pp. 25-35.

32 Charles Orser, "Beneath the Material Surface of Things: Commodities, Artifacts, and Slave Plantations", Historical Archaeology, v. 26, n. 3 (1992), p. 95.

33 Potter Jr., "What is the Use", pp. 98-9. 
Para a arqueologia afro-americana, a crítica marxista foi importante na medida em que destacou que a dimensão de poder era inerente às relações sociais no espaço das plantations, uma preocupação não considerada pelos arqueólogos processualistas em suas análises de identificação e explanação de padrões. Porém, esses autores adotaram uma perspectiva unidirecional de poder, vendo-o como concentrado nas mãos do proprietário. Nessa perspectiva, a camada senhorial, a partir do controle dos recursos materiais e do uso de ideologias como paternalismo, racismo e religião, dominava uma população escravizada que se mantinha passiva e submissa. Embora seja inegável a assimetria dessas relações sociais, tais abordagens desconsideravam a possível habilidade dos cativos para negociar suas vidas e impor limites a tal dominação. Esses grupos poderiam ter se utilizado de estratégias de negociação social bastante sutis, porém mais politicamente efetivas do que as respostas automáticas à dominação usualmente denominadas resistência. Do mesmo modo, não deve ser desprezada a habilidade que eles podem ter tido para rejeitar ou assimilar seletivamente as possíveis ideologias e os valores pretensamente impostos pela camada senhorial.

\section{Poder, bidirecionalidade e dinâmica interna das comunidades afro-americanas}

Uma visão mais equilibrada, bidirecional, das relações de poder tem sido desenvolvida nos trabalhos de arqueologia afro-americana desde meados de década de 1990, que passaram a dar atenção ao estudo da dinâmica interna das comunidades afro-americanas e a explorar de que modo a cultura material euro-americana foi utilizada por esses grupos como suporte de suas práticas sociais e culturais. Essas abordagens se inserem em um contexto de desenvolvimento do pensamento social na arqueologia histórica marcado pela rejeição aos modelos teóricos que adotam somente a perspectiva dos grupos politicamente dominantes, focalizando a agência dos grupos subordinados a partir de abordagens recursivas que consideram as trocas e negociações entre os grupos envolvidos. Este é o caso dos estudos de Wilkie, Young e Thomas, a partir de diferentes perspectivas teóricas. ${ }^{34}$

34 Laurie Wilkie, Ethnicity, Community and Power: an Archaeological Study of the African-American Experience at Oakley Plantation, Louisiana, Columbia: The University of South Carolina, 1994; 
Wilkie aplicou uma abordagem contextual visando a analisar os modos pelos quais os afro-americanos da plantation Oakley, Louisiana, compartilharam tradições étnicas e se envolveram em negociações de poder com os proprietários entre 1790 e 1940, explorando de que maneira os afro-americanos usaram a cultura material euro-americana como suporte de práticas culturais de origem africana. Segundo a autora, as tradições culturais e a visão de mundo mantidas por esses grupos em Oakley constituíram suas "ferramentas de poder", atuando na manutenção da coesão do grupo e como base de suas estratégias de negociação. ${ }^{35}$ Porém, em seu esforço para compreender toda a cultura material dos contextos afro-americanos de um ponto de vista êmico, com base na possível lógica cultural dos sujeitos em questão, muito do trabalho de Wilkie cai no domínio da especulação. Por exemplo, ao discutir os usos das peças de chá presentes nesses contextos, ela considerou que suas funções envolveriam, possivelmente, desde o consumo de água e café, passando pela contenção de condimentos, até o uso dentro de um sistema medicinal tradicional relacionado com o consumo de chás medicinais. Sua preocupação em tentar explorar todas as possibilidades das práticas culturais afro-americanas associadas a todas as categorias de artefatos, muitas vezes sem elementos convincentes que sustentem tais possibilidades, torna seu trabalho tedioso e especulativo.

Também voltado para a dinâmica interna de uma comunidade de senzala é o trabalho de Young sobre a plantation Locust Grove, Kentucky. ${ }^{36}$ Utilizando a abordagem de gerenciamento de risco, ela explorou quatro das estratégias que os cativos empregaram para interagir com as situações de risco impostas pelos proprietários: prevenção, transferência, estocagem e compartilhamento. A prevenção incluía o uso de rituais para evitar infortúnios, sinalizado por itens de possível caráter mágico-religioso, tais como uma moeda chinesa com um buraco quadrangular em seu centro, uma americana com quatro incisões na borda, outra de

Amy Young, "Risk Management Strategies among African-American Slaves at Locust Grove Plantation", International Journal of Historical Archaeology, v. 1, n. 1 (1997), pp. 3-29; Brian Thomas, "Power and Community: the Archaeology of Slavery at the Hermitage Plantation", American Antiquity, v. 63, n. 4 (1998), pp. 531-55.

35 Wilkie, Ethnicity, p. 39.

36 Young, "Risk Management Strategies".

170 Afro-Ásia, 49 (2014), 159-198 
prata com incisão em forma de cruz em uma das faces, uma conta de vidro azul facetada, cristais de lustres, uma colher com o signo $\mathrm{x}$ inciso no cabo, dentre outros. A transferência consistia na alocação de recursos para os necessitados, por meio de roubo ou de doação, sendo a primeira possibilidade levantada diante da alta incidência de ossos de filhotes de porcos nas amostras, que poderiam ter sido roubados do proprietário. A prática da estocagem consistia em guardar os excedentes para uso nos momentos de necessidade, conforme apontado pela presença, na base das senzalas, de buracos (pit cellars) destinados a esse fim. A possibilidade de compartilhamento foi analisada com base no uso de itens materiais similares nas senzalas, tais como conjuntos de louças e botões, sendo usualmente os itens de maior valor os mais compartilhados, denotando estratégias de construção de laços de solidariedade entre os ocupantes de diferentes senzalas.

Thomas discutiu a distribuição das louças finas na plantation Hermitage, Tennessee, como uma estratégia dos proprietários para estabelecer uma hierarquia material entre os cativos, concedendo as louças de maior valor aos ocupantes das senzalas mais próximas da sede e as mais baratas aos das senzalas mais distantes. ${ }^{37}$ Segundo ele, essa distribuição hierárquica serviu mais para ilustrar a visão que o proprietário tinha da organização da plantation do que para determinar a verdadeira organização social da comunidade escravizada, pelo fato de esses grupos não terem atribuído àquelas peças a mesma significância social que a camada senhorial lhes dava. Os cativos teriam construído uma imagem alternativa da sua comunidade, baseada em seus próprios sistemas de valores e materialmente representada por itens que não faziam parte do provisionamento básico que lhes era fornecido pelos proprietários, tais como contas de colar, botões, moedas, garrafas de vidro e amuletos. Tais itens seriam representativos de uma economia interna da senzala e poderiam ter sido usados como símbolos para reforçar um senso compartilhado de identidade.

37 Thomas, "Power and Community". 


\section{A arqueologia crítica da raça}

Ainda na década de 1990, um grupo de acadêmicos teceu fortes críticas ao conceito de etnicidade então em voga na arqueologia afro-americana. O problema central apontado por esses autores consistia na subestimação da ideologia do racismo e de seu papel central na definição dos grupos étnicos. ${ }^{38}$ Defendiam, assim, que o foco das pesquisas deveria ser direcionado, por um lado, para o papel da ideologia racista na legitimação da escravidão e, por outro, para o entendimento de como os grupos afro-americanos construíram uma cultura que resistia ao racismo, ao mesmo tempo em que usaram essa mesma ideologia como um elemento de coesão do grupo.

Epperson, ao analisar uma série de eventos relacionados com o cemitério africano de Nova York (o African Burial Ground), examinou o discurso racista construído pelos ingleses, no século XVIII, com o propósito de justificar a exploração dos africanos e dos ameríndios. ${ }^{39}$

Mullins, por sua vez, discutiu como a ideologia racista, no final do século XIX, foi divulgada a partir de quinquilharias industrializadas, como estatuetas que estereotipavam os povos não europeus, destinadas ao consumo dos brancos de classe média, ${ }^{40}$ e demonstrou que muitos afro-americanos também decoraram suas casas com essas mesmas quinquilharias, como forma de desafiar a exclusividade dos brancos no consumo desses itens e, em consequência, as ideologias a eles vinculadas.

As arqueologias da raça contribuíram para expor a ideologia do racismo, subestimada nas abordagens anteriores e, assim, adicionaram uma conotação mais política à noção de etnicidade afro-americana. Um problema, porém, é a suposição generalizante de que os afrodescendentes, em função da cor de sua pele, tenham tido experiências sociais semelhantes e utilizado esse mesmo critério como uma estratégia de

\footnotetext{
38 David Babson, "The Archaeology of Racism and Ethnicity on Southern Plantations", Historical Archaeology, v. 24, n. 4 (1990), pp. 20-8; Terrence Epperson, "Constructing Difference: the Social and Spatial Order of the Chesapeake Plantation", in Singleton (org.), "I, too, am America”, pp. 159-72; Paul Mullins, "Racializing the Parlor: Race and Victorian Bric-a-Brac Consumption", in Orser (org.), Race and the Archaeology, pp.158-76; Charles Orser, "The Challenge of Race to American Historical Archaeology", American Anthropologist, v. 100, n. 3 (1998), pp. 661-8. 39 Epperson, "Constructing Difference".

40 Mullins, "Racializing the Parlor". 
coesão social e resistência à dominação da sociedade branca. Essa generalização cai na armadilha de transportar, indiscriminadamente para o passado, percepções do atual contexto social norte-americano. No Brasil, há muito tempo os estudiosos da escravidão já constataram que critérios pautados em identificação social e cultural foram mais determinantes para a população escravizada como mecanismos de coesão social do que a simples ascendência africana. ${ }^{41}$

\section{Crioulização, reapropriação e práticas rituais}

As mudanças de perspectiva que marcaram a arqueologia afro-americana na década de 1990 envolveram ainda a aplicação de modelos de trocas culturais mais sofisticados do que o paradigma da aculturação. Os arqueólogos, sobretudo a partir do trabalho de Ferguson, ${ }^{42}$ começaram a abordar as possíveis maneiras pelas quais os afro-americanos não somente se reapropriaram da cultura material hegemônica a partir de seus próprios referenciais mas também exerceram influências sobre a sociedade euro-americana. Começou, assim, a ser adotado o modelo de crioulização que consiste em um processo que envolve interações e trocas multiculturais que levaram a novas formas culturais, buscando, desse modo, incluir o efeito da experiência do Novo Mundo sobre todos os grupos populacionais, inclusive os euro-americanos. ${ }^{43}$ Tem sido reconhecido como um processo simultaneamente cognitivo e material, que leva à criação de identidades sociais crioulas entre europeus e africanos, ao mesmo tempo em que ocorre a adaptação às condições econômicas, sociais e ecológicas do novo contexto.

Ao analisar as plantations da Jamaica a partir de evidências como arquitetura e uso do espaço, hábitos alimentares e práticas de saúde, Delle observou que tanto os euro-crioulos quanto os afro-crioulos constituíram

41 Ver, por exemplo, Mary Karasch, A vida dos escravos no Rio de Janeiro, São Paulo: Companhia das Letras, 2000; Stuart Schwartz, Escravizados, roceiros e rebeldes, Bauru: EDUSC, 2001; João J. Reis, Rebelião escrava no Brasil: a história do Levante dos Malês, São Paulo: Companhia das Letras, 2003.

42 Leland Ferguson, Uncommon Ground: Archaeology and Early African America, 1650-1800, Washington/London: Smithsonian Institution Press, 1992.

43 Singleton, "Cultural Interaction", p. 177; S. Dawdy, "Creolization: Preface", Historical Archaeology, v. 34 , n. 3 (2000), p. 1. 
sociedades distintas daquelas de suas matrizes, com regras pautadas, no caso dos euro-crioulos, nos precedentes ingleses, mas transformadas tanto pelas influências africanas e afro-crioulas quanto pela adaptação às condições climáticas e ecológicas de uma ilha tropical. No caso dos afro-crioulos, tal processo foi pautado em referenciais africanos, porém influenciados pela presença da sociedade dominante europeia e euro-crioula. ${ }^{44}$

O uso do modelo de crioulização levou os arqueólogos a um esforço para entender a cultura material dos contextos afro-americanos com base nos referenciais culturais próprios desses grupos. Ao analisar o material de uma senzala da plantation Clifton, Bahamas, Wilkie alegou que os cativos se apropriaram seletivamente dos bens materiais europeus que melhor refletiam suas sensibilidades culturais, possibilitando-lhes, desse modo, construir identidades crioulizadas no Novo Mundo. Nessa plantation, esses grupos mantinham suas próprias hortas e podiam vender os excedentes produzidos no mercado regional, o que permitia a acumulação de um pecúlio, possibilitando-lhes condições de comprar seus próprios bens materiais. Na senzala, esses grupos privilegiaram as peças policrômicas, pintadas à mão e anulares, ao passo que os proprietários privilegiaram peças monocromáticas decalcadas. Para Wilkie, a ênfase dos cativos nas louças coloridas anulares refletiria influências culturais africanas, relacionadas com as tradições artísticas dos bacongos, um grupo étnico da África Central, que enfatizam elementos organizados em faixas concêntricas, dentro das quais são adicionados desenhos como pontos, zigue-zagues, e cruzes. ${ }^{45}$

O papel dos afro-americanos como consumidores ativos, que selecionavam itens europeus industrializados com base em suas próprias percepções culturais, está também presente no trabalho de Stine, Cabak e Groover. ${ }^{46}$ Para eles, a presença maciça de contas de colar azuis nos sítios afro-americanos seria indicativa de um fenômeno pancultural de origem africana, constituindo-se em um aspecto do consumismo afro-americano dentro de uma economia informal nas senzalas.

${ }^{44}$ James Delle, "The Material and Cognitive Dimensions of Creolization in Nineteenth-Century Jamaica", Historical Archaeology, v. 34, n. 3 (2000), pp. 56-72.

45 Laurie Wilkie, "Culture Bought: Evidence of Creolization in the Consumer Goods of an Enslaved Bahamian Family", Historical Archaeology, v. 34, n. 3 (2000), pp. 10-26.

46 Linda Stine, Melanie Cabak e Mark Groover, "Blue Beads as African-American Cultural Symbols", Historical Archaeology, v. 30, n. 3 (1996), pp. 49-75. 
Ao tentar entender como os cativos usaram uma cultura material euro-americana com base em regras subjacentes de uma gramática que se manteve principalmente africana, ${ }^{47}$ os arqueólogos começaram a prestar mais atenção ao registro arqueológico desses grupos em termos de suas particularidades bem como às relações contextuais entre artefatos e estruturas, buscando entender os modos específicos pelos quais a cultura material foi empregada e ressignificada em práticas diversificadas, muitas vezes pautadas em referenciais bastante diferenciados daqueles da cultura hegemônica. Esse é o caso dos estudos que se ocupam das práticas religiosas dos africanos na diáspora. Quando não explicitado, o modelo de crioulização está implícito em tais trabalhos, na medida em que enfatizam os modos pelos quais sistemas de crenças de matriz africana foram adaptados nas Américas e guiaram o uso de determinadas categorias de artefatos.

Ferguson interpretou as marcas cruciformes na base de tigelas cerâmicas artesanais encontradas no leito de rios adjacentes a plantations da Geórgia como um cosmograma típico dos bacongos, em vista da associação daquelas peças com a água, um elemento central de sua cosmologia, representando a fronteira entre o mundo dos vivos e o mundo dos mortos. ${ }^{48}$

Brown, ao trabalhar com contextos de deposição posteriores à Guerra Civil americana (após 1865) na plantation Levi Jordan, Texas, identificou possíveis evidências de atividades rituais afro-americanas no subsolo do quarto de uma senzala que ele associou à provável ocupação de um curandeiro-mágico. Reunido em um dos cantos do recinto encontrava-se um conjunto de artefatos interpretado como um "kit ritual", constituído de bases de caldeirões de ferro, cubos de giz branco, crânios de pássaros, garras de um animal, conchas marinhas, pequenas bonecas e um grande número de pregos, alfinetes, lâminas de faca e pedras lascadas. Esse "kit ritual" relacionava-se espacialmente com três conjuntos de artefatos encontrados nos três outros cantos do mesmo recinto, formando um possível cosmograma cruciforme. Para o autor, esses conjuntos sugerem a manutenção de um sistema de crenças

47 Ferguson, Uncommon Ground, p. xlii.

48 Ferguson, Uncommon Ground. 
de base africana, que tinha por propósito controlar o mundo exterior a partir da manipulação do mundo sobrenatural. ${ }^{49}$

Leone e Fry relataram o achado de doze grupos de artefatos em três casas de Annapolis, Maryland, dos séculos XVIII e XIX, que estariam relacionados com práticas religiosas africano-ocidentais que teriam dado origem ao hoodoo afro-americano. Esses conjuntos de artefatos (caches) haviam sido colocados sob as bases das lareiras, abaixo do canto nordeste de uma sala e próximos às portas. Seu conteúdo inclui pregos e alfinetes, discos perfurados assim como botões, moedas, conchas, anéis, fragmentos cerâmicos, seixos, pedaços de vidro e de cristais. ${ }^{50}$

Outros estudos têm examinado os possíveis significados religiosos de artefatos encontrados em senzalas, como contas de vidro azuis, moedas chinesas, moedas com cruzes incisas, moedas perfuradas, cristais de lustres, cristais de quartzo, colheres com cruzes incisas no cabo, figas e outros amuletos em forma de mão, osso de pênis de racon (uma espécie de roedor), fragmentos de louça retrabalhados em forma de discos e tampas de vidros. ${ }^{51}$ Embora muitos desses objetos tenham sido de manufatura europeia ou euro-americana, segundo os autores eles teriam sido modificados ou reapropriados com base em significados de origem africana.

Finalmente, alguns acadêmicos têm notado a presença, em sepultamentos afro-americanos, de oferendas no topo e ao redor dos túmulos, uma prática também amplamente documentada na África Ocidental e Central..$^{52}$

\footnotetext{
49 Kenneth Brown, "Material Culture and Community Structure: the Slave and Tenant Community at Levi Jordan's Plantation, 1848-1892", in Larry Hudson Jr. (org.), Working toward Freedom: Slave Society and Domestic Economy in the American South (New York: University of Rochester Press, 1994), p. 114.

50 Mark Leone e Gladys-Marie Fry, "Spirit Management among Americans of African Descent", in Orser (org.), Race and the Archaeology, pp. 143-57.

51 Eric Klingholfer, "Aspects of Early Afro-American Material Culture: Artifacts from the Slave Quarters at Garrison Plantation, Maryland”, Historical Archaeology, v. 21, n. 2 (1987), pp. 112-9; Aaron Russel, "Material Culture and African-American Spirituality at the Hermitage", Historical Archaeology, v. 31, n. 2 (1997), pp. 63-80; Laurie Wilkie, "Magic and Empowerment on the Plantation", Southeastern Archaeology, v. 14, n. 2 (1995), pp. 136-57; Amy Young, "Archaeological Evidence of African-Style Ritual and Healing Practices in the Upland South, Tennessee Anthropologist, v. 21, n. 2 (1996), p. 139-55.

52 H. Bolton, "Decoration of Graves of Negroes in South Carolina", Journal of American Folklore, v. 4 (1891), p. 214; John McCarthy, "Material Culture and the Performance of Sociocultural Identity", in Ann Martin e Ritchie Garrison (orgs.), American Material Culture: the Shape of the Field (Delaware: Henry Francis du Pont Winterthur Museum, 1997), pp. 359-79.
} 
As oferendas incluem conchas de ostras, seixos brancos, garrafas de vidro, cerâmicas quebradas, xícaras, pires, tigelas, lampiões de querosene, dentre outros objetos, que teriam sido itens pessoais do morto ou usados por ele antes de sua morte. ${ }^{53}$

Apesar de considerado um modelo mais equilibrado do que o de aculturação, na medida em que tenta entender a cultura material dos contextos afro-americanos como o produto de reapropriações ou trocas culturais, o modelo de crioulização também tem sido sujeito a críticas.

Singleton observou que o foco no processo de crioulização obscurece a identidade cultural de grupos étnicos específicos. ${ }^{54} \mathrm{~A}$ ampla literatura sobre a experiência escrava africana no Brasil tem demonstrado que grupos de diferentes regiões da África tenderam a reconstruir identidades diferenciadas, pautadas em referenciais culturais compartilhados em suas regiões de origem, configurando as chamadas nações africanas. ${ }^{55}$ Essa segmentação dos africanos ao longo de linhas identitárias conformadas na diáspora não tem sido contemplada em tais estudos, pois partem da premissa de que as populações africanas nas Américas rapidamente se homogeneizaram, construindo culturas crioulas como uma resposta às condições da escravidão. Singleton alegou ainda que o modelo de crioulização é estático, por assumir que uma gramática própria de uso dos artefatos mantém-se invariável, desconsiderando o contexto social. Gundaker fez coro a essa crítica, destacando as limitações do modelo ao desconsiderar a coexistência das linguagens crioulas com as metropolitanas e, assim, o papel ativo dos atores em sua capacidade de manipular mais de um tipo de linguagem, de estilo comportamental ou de repertório material de acordo com os seus interesses. ${ }^{56}$

\footnotetext{
53 Ver Bolton, "Decoration of Graves"; E. Ingersol, "Notes and Queries: Decoration of Negro Graves", Journal of American Folklore, v. 5 (1892), pp. 68-9; J. Combes, "Ethnography, Archaeology, and Burial Practices Among Coastal South Carolina Blacks", The Conference on Historic Sites Archaeology Papers, 7 (1971), pp. 52-61.

${ }_{54}$ Singleton, "Cultural Interaction", p. 177.

55 Ver, por exemplo, Karasch, A vida dos escravos; Mieko Nishida, Slavery and Identity: Etnicity, Gender, and Race in Salvador, Brazil, Bloomington/Indianapolis: Indiana University Press, 2003; Reis, Rebelião escrava; John Thronton, Africa and Africans in the Making of the Atlantic World, Cambridge: Cambridge University Press, 1998.

56 Singleton, "Cultural Interaction", p. 177; G. Gundaker, "Discussion: Creolization, Complexity, and Time", Historical Archaeology, v. 34, n. 3 (2000), pp. 124-33.
} 
O modelo de crioulização, particularmente em sua variante gramatical, é fundamentado em uma rígida noção de estrutura, na qual a ação dos indivíduos depende de regras culturais pré-determinadas. Essa estrutura não deixa margem a ações criativas e estratégicas, em que os agentes envolvidos podem adotar diferentes padrões de comportamento em detrimento do contexto social, visando à realização de metas específicas, que a teoria social contemporânea convencionou chamar de agência. O caso das irmandades católicas criadas pelas comunidades escravizadas no Brasil e na América hispânica como estratégias de ajuda mútua é um exemplo. Os filiados a essas irmandades adotavam, em muitos casos, uma identidade religiosa católica, que era exposta ao domínio público, controlada pela sociedade luso-brasileira, ao mesmo tempo em que mantinham práticas religiosas de matriz africana em espaços privados, às escondidas da sociedade dominante ${ }^{57}$ Essa manipulação instrumental da cultura luso-brasileira pela população africana e afro-brasileira não se limitava somente ao domínio religioso, estendendo-se a outras facetas de sua vida cotidiana. Assim, do mesmo modo que eles poderiam manter uma (ou várias) "gramática(s) africana(s)" nas interações intragrupo, também poderiam empregar uma "gramática luso-brasileira", instrumentalmente aplicada em suas interações com a sociedade dominante branca.

\section{Herança cultural e colonoware}

Uma categoria material que perpassa a maior parte das discussões aqui referidas, mas que, pelas suas especificidades, deve ser abordada à parte, é a cerâmica artesanal de produção local ou regional, denominada, nos Estados Unidos, de colonoware. Encontrada desde a década de 1960 em contextos históricos, a questão das supostas influências africanas

\footnotetext{
57 Sobre as irmandades de escravizados no Brasil, ver exemplos em Karasch, A vida dos escravos, pp. 130-3; Mariza Soares, Devotos da cor: identidade étnica, religiosidade e escravidão no Rio de Janeiro, século XVIII, Rio de Janeiro: Civilização Brasileira, 2000; Elizabeth Kiddy, "Kings, Queens, and Judges: Hierarchy in Lay Religious Brotherhoods of Blacks, 1750-1830”, in José Curto e Renée Soloudre-LaFrance (orgs.), Africa and the Americas: Interconections During the Slave Trade (Trenton: Africa World Press, 2005), pp. 95-126. Sobre práticas religiosas de matriz africana, ver James Sweet, Recreating Africa: Culture, Kinship, and Religion in the African-Portuguese World, 1441-1770, Chapel Hill/London: The University of Carolina Press, 2003; Rachel Harding, A Refuge in the Thunder: Candomblé and Alternative Spaces of Blackness, Bloomington/ Indianapolis: Indiana University Press, 2000.
} 
sobre esse material tem sido assunto de um amplo debate, dividindo os acadêmicos que defendem essa interpretação e aqueles que a rejeitam. ${ }^{58}$

A gênese desse debate remonta aos anos de 1960, quando Hume, ${ }^{59}$ escavando sítios em área de colonização inglesa na Virgínia, encontrou amostras de uma cerâmica grosseira, sem esmalte, em formas predominantemente não europeias e classificou-a como Colono-Indian Ware, por considerá-la similar às formas ameríndias encontradas na Virgínia. Segundo ele, os ameríndios teriam produzido esses vasilhames em estilo aceito pelos afro-americanos para vendê-los nas plantations. Nos anos de 1970, South e Polhemus questionaram essa interpretação,${ }^{60}$ sugerindo uma origem afro-americana para essa cerâmica, em vista de sua semelhança morfológica com cerâmicas modernas da região de Gana e da Nigéria, e Ferguson apontou uma semelhança quanto à técnica de manufatura e o acabamento de superfície.$^{61}$ Posteriormente, Deetz constatou fortes correlações entre o padrão demográfico africano na Virgínia e na Carolina do Sul e a distribuição cronológica da colonoware nesses dois estados, em ambos os casos iniciando-se no final do século XVII, com um pico de popularidade entre 1750 e 1800 , e declinando intensamente no início do século XIX. ${ }^{62}$

\footnotetext{
58 Posições a favor das influências africanas sobre a colonoware incluem Deetz, In Small Things; M. Emmerson, "African Inspirations in a New World Art and Artifact: Decorated Pipes from Chesapeake", in Singleton (org.), "I, too, Am America”, pp. 47-82; Allan Meyers, "West African Tradition in the Decoration of Colonial Jamaican Folk Pottery”, International Journal of Historical Archaeology, v. 3, n. 4 (1999), pp. 201-24; James Petersen e J. Waters, "Continuity and Syncretism in Afro-Caribbean Ceramics from the Northern Lesser Antilles", in J. Haviser (org.), African Sites Archaeology in the Caribbean (Princeton: Markus Wiener, 1988), pp. 157-95; Wheaton e Garrow, "Acculturation". Posições críticas incluem DeCorse, "Oceans Apart”, pp. 132-58; Matthew Hill, "Ethnicity Lost? Ethnicity Gained? Information Functions of African Ceramics in West Africa and North America", in R. Auger, M. Glass, S. McEachern e P. McCartney (orgs.), Ethnicity and Culture: Proceedings of the Eighteenth Annual Chacmool Conference (Calgary: University of Calgary, 1987), pp. 135-9; L. Daniel Mouer et alii, "Colonoware Pottery, Chesapeake Pipes, and Uncritical Assumptions", in Singleton (org.), "I, too, Am America”, pp. 83-115; Mark Houser e Christopher DeCorse, "Low-fired earthenwares in the African diaspora: problems and prospects", International Journal of Historical Archaeology, v. 7, n. 1 (2003), p. 67-98; Merry Posnanski, "West Africanist Reflections on African-American Archaeology”, in Singleton (org.), "I, too, Am America”, pp. 21-38.

59 Ivor Noel Hume, "An Indian Ware of the Colonial Period", Quarterly Bulletin, Archaeological Society of Virginia, v. 17 (1962), p. 1.

${ }^{60}$ Citados em Leland Ferguson, "Looking for the 'Afro' in Colono-Indian Pottery", in Robert Schuyler (org.), Archaeological Perspectives on Ethnicity in America (Baywood: New York, 1980), pp.14-28.

${ }^{61}$ Ferguson, "Looking for the 'Afro"”; Ferguson, Uncommon Ground.

62 Deetz, In Small Things.
} 
Dois exemplos de trabalhos voltados para a reprodução de tradições estilísticas africanas no Novo Mundo são a pesquisa de Meyers sobre as cerâmicas afro-jamaicanas do século XVII do sítio Port Royal e o estudo de Emmerson sobre cachimbos decorados produzidos nas plantations da região de Chesapeake. ${ }^{63}$ Meyers, trabalhando com uma amostra bastante reduzida de cerâmicas decoradas, apontou influências africano-ocidentais, sobretudo da região de Gana, sobre os motivos estampados, e Emmerson acrescentou que a emergência de alguns tipos de cachimbos de produção local, como aqueles com formas facetadas, teria ocorrido nas plantations de Chesapeake simultaneamente à chegada de grande número de africanos procedentes da África Ocidental. Os motivos decorativos de alguns cachimbos apresentam marcante semelhança com tradições decorativas daquela região, tais como os motivos denominados double bell e Kwardata além de semelhanças quanto a técnicas decorativas, tais como o pontilhado, o estampado e o preenchimento com argila branca.

No entanto, Hill criticou tais correlações, alegando que os vasilhames colonoware são similares a qualquer cerâmica produzida por grupos nativos no mundo, de tal modo que tanto africanos quanto ameríndios poderiam ter produzido essas peças. ${ }^{64}$ Posnanski e DeCorse compartilharam essa visão, observando que essa cerâmica utilitária e pobremente decorada não se assemelha à sofisticação das tradições ceramistas da África Ocidental. ${ }^{65}$ Do mesmo modo, Mouer et al. criticaram a opinião de Emmerson por ter subestimado evidências históricas, arqueológicas e etnográficas de que ameríndios poderiam ter produzido os cachimbos de Chesapeake assim como os vasilhames cerâmicos, visto que muitos dos aspectos por ele considerados de origem africana ocidental foram comuns nas tradições regionais pré-coloniais e indígenas históricas. ${ }^{66}$

Essas críticas de arqueólogos que trabalham em contextos da África, do Caribe e dos Estados Unidos demonstram o quão problemático é assumir a existência de correlações diretas entre tradições ceramistas da África e das Américas. Deve-se levar em conta que muitos dos estudos

\footnotetext{
${ }^{63}$ Meyers, "West African Tradition"; Emmerson, "African Inspirations".

${ }^{64}$ Hill, "Ethnicity Lost?".

65 Posnanski, "West Africanist Reflections"; DeCorse, "Oceans Apart".

${ }^{66}$ Mouer et al., "Colonoware Pottery".
} 
que defendem influências africanas sobre a colonoware têm, de fato, se baseado em evidências seletivas que constituem exceções no universo material dessas populações revelado por meio da arqueologia, como é o caso do trabalho de Meyers, baseado em uma amostra de apenas 28 fragmentos decorados, correspondendo apenas a 3\% do total da amostra de colonoware.$^{67} \mathrm{Na}$ verdade, a decoração é uma dimensão praticamente inexpressiva das amostras de colonoware encontradas nos Estados Unidos e no Caribe ${ }^{68} \mathrm{e}$ a baixa proporção de colonoware decorada torna questionável o estabelecimento de correlações com as tradições ceramistas africanas ricamente decoradas.

Mais recentemente, alguns arqueólogos têm proposto abandonar esse debate polarizado e analisar a colonoware em termos do processo de interação que ela representa. Nesse sentido, Orser a considerou um tipo de artefato mutualista, usado por afro-americanos e nativoamericanos como uma expressão de resistência ao colonialismo europeu. Singleton e Bograd, no mesmo tom, alegaram que o foco sobre a identidade dos produtores desse material se baseia em uma concepção essencialista e, portanto, estática de identidade étnica, que limita o seu potencial no estudo dos cenários coloniais e multiculturais. Para esses autores, é mais produtivo abordar a colonoware como um tipo de artefato intercultural, imbuído de significados e usos cambiáveis.

O principal problema, porém, com essa perspectiva, é a tentativa de superar essa questão abandonando-a, ao subestimar a importância da identidade dos produtores e usuários desses artefatos. Embora o projeto colonialista tenha tido um impacto avassalador tanto para africanos quanto para ameríndios, esses dois grupos tiveram experiências bastante diferenciadas no desenvolver desse processo. Certamente, um africano — ou, mais provavelmente, uma africana - , ao produzir um vasilhame cerâmico em um contexto de plantation, o fazia com base em referenciais muito distintos daqueles de um ameríndio - ou, mais provavelmente, uma ameríndia - que produzia um vasilhame em uma aldeia visando à sua comercialização ou ao seu uso próprio. Deve-se ainda levar em conta que os principais laços sociais e culturais dessa ceramista estariam

67 Meyers, "West African Tradition".

${ }_{68}$ Meyers, "West African Tradition”, p. 209; Petersen e Waters, "Continuity and Syncretism”, p. 185. 
muito mais ligados à sua comunidade da senzala do que a populações indígenas com as quais ela poderia ter tido pouca, se alguma, afinidade cultural. Desse modo, a explanação da colonoware como um artefato intercultural deve ser dependente do contexto, sendo necessário, em primeiro lugar, estabelecer-se, em cada caso, o nível de interação entre africanos e afrodescendentes, ameríndios e euro-americanos, em vez de assumir-se a priori que teria ocorrido uma intensa interação.

\section{A arqueologia da diáspora africana no Brasil}

Em contraste com os Estados Unidos, a arqueologia da diáspora africana ainda é recente no Brasil. Duas revisões da literatura tratam do tema: ${ }^{69}$ o trabalho de Funari discute as pesquisas em quilombos, sobretudo o de Palmares, enfatizando a questão dos processos de troca e de interação entre quilombolas e os demais grupos das regiões por eles ocupadas, sem mencionar outros contextos estudados nos últimos anos, enquanto o de Singleton e Souza faz uma ampla revisão dos principais temas e pesquisas nos Estados Unidos, em Cuba e no Brasil, até o ano de 2005, apreciando, na seção referente ao Brasil, a arqueologia dos quilombos de Minas Gerais e de Palmares e as pesquisas em senzalas no Rio de Janeiro, Goiás, Mato Grosso e Rio Grande do Sul.

\section{$A$ arqueologia e a etnoarqueologia de quilombos}

No Brasil, a arqueologia da escravidão foi inaugurada no final da década de 1970, com os estudos de Guimarães e Lanna em cinco quilombos do Vale do Jequitinhonha e da Serra da Canastra, Minas Gerais. ${ }^{70}$ Os autores descreveram o material coletado - fragmentos cerâmicos, cachimbos, panelas de ferro e de esteatita, fragmentos de louça e de garrafas de vidro, ossos de mamíferos e seixos rolados marcados com cruzes em vermelho

\footnotetext{
${ }^{69}$ Pedro Funari, "The Archaeological Study of African Diaspora in Brazil", in A. Ogundiram e T. Falola (orgs.), Archaeology of Atlantic Africa and the African Diaspora (Bloomington: Indiana University, 2007), pp. 355-71; Thereza Singleton e Marcos A. Souza, "Archaeologies of the African Diaspora: Brazil, Cuba, and the United States”, in T. Majewski e D. Gaimster (orgs.), International Handbook of Historical Archaeology (New York: Springer, 2009), pp. 449-69.

${ }^{70}$ Carlos Guimarães e Ana Lanna, “Arqueologia de quilombos em Minas Gerais”, Pesquisas: Série Antropológica, n. 31 (1980), pp. 147-64.
} 
— e destacaram a implantação de todos esses sítios em pontos de difícil acesso porém próximos a rotas comerciais, atribuindo-a a estratégias utilizadas pelos quilombolas para evitar ou dificultar o acesso dos capitães do mato aos locais em que habitavam, ao mesmo tempo em que mantinham a acessibilidade aos recursos da sociedade envolvente. Em dois desses sítios, também foram localizados painéis de pinturas rupestres feitas a carvão. As representações do Quilombo da Cabaça apresentam cenas de um navio veleiro, de uma batalha e de um banguê — uma rede suspensa em um pedaço de pau carregada por duas pessoas, utilizada para o transporte individual. ${ }^{71}$ Para Guimarães, essas cenas representam as fases principais na vida de um africano escravizado, indo da captura na África, passando pela travessia do Atlântico e finalizando com o trabalho compulsório realizado no Brasil como carregador.

No final dos anos 1980, uma equipe de pesquisadores realizou escavações no Quilombo do Ambrósio, Minas Gerais, localizando vestígios de construções de pau a pique e recuperando itens de uso cotidiano, como cachimbos e vasilhames cerâmicos além de restos de alimentos. ${ }^{72}$ Lamentavelmente, essas pesquisas não tiveram continuidade, tendo sido publicados apenas seus resultados iniciais.

Em 1992 e 1993, Orser e Funari realizaram escavações na Serra da Barriga, Alagoas, na área do Quilombo dos Palmares, recuperando amostras de cerâmicas indígenas, cerâmicas coloniais e louças europeias. ${ }^{73} \mathrm{O}$ material -2.488 fragmentos recolhidos em 14 sítios -74 serviu de base para uma série de discussões, tais como a problematização da identidade

71 Carlos Guimarães, “Arqueologia do quilombo: arquitetura, alimentação e arte (Minas Gerais)", in C. Moura (org.), Os quilombos na dinâmica social do Brasil (Maceió: UFAL, 2001), pp. 35-58.

72 Carlos Guimarães, Ana Santos, Betânia Gonçalves e Liliana Porto, "O quilombo do Ambrósio: lenda, documentos e arqueologia", Estudos Ibero-Americanos, v. 16, n. 1-2 (1990), pp.161-74.

73 Charles Orser e Pedro Funari, "A pesquisa arqueológica inicial em Palmares", Estudos Ibero-Americanos, n. 18 (1992), pp. 53-69. Pedro Funari, por sua vez, escreveu, ao longo dos últimos vinte anos, um grande número de artigos e capítulos de livros sobre a pesquisa arqueológica em Palmares. Um bom detalhamento das pesquisas, fornecendo informações sobre o campo e o material encontrado está em “A arqueologia de Palmares”, in João Reis e Flávio Gomes (orgs.), Liberdade por um fio: história dos quilombos no Brasil (São Paulo: Companhia das Letras, 1996), pp. 26-51.

74 Pedro Funari, "Etnicidad, identidad y cultura material: un estudio del cimarrón Palmares, Brasil, siglo XVII", in Andrés Zarankin e Félix Acuto (orgs.), Sed non satiata: teoria social en la arqueología latinoamericana contemporánea (Buenos Aires: Tridente, 1999), pp. 77-96. 
étnica palmarina ${ }^{75}$ a integração de Palmares no colonialismo global ${ }^{76}$ e as possíveis diferenciações internas da sua estrutura social em vista da composição multiétnica de seus habitantes. ${ }^{77}$ Entretanto, pesquisas arqueológicas posteriores, realizadas em 1996 e 1997 por Allen, ${ }^{78}$ identificaram uma forte descaracterização do sítio, decorrente sobretudo de terraplenagens que teriam alterado os padrões de distribuição espacial do material arqueológico, levando-o a afirmar que, até aquele momento, "não sabemos quase nada da vida palmarina através de estudos arqueológicos". ${ }^{79}$ Allen ainda verificou no sítio em questão vestígios de uma intensa ocupação indígena pré-colonial.

Pesquisas mais recentes incluem a tese de doutorado de Carle, sobre quilombos do Rio Grande do Sul, ${ }^{80}$ e estudos etnoarqueológicos em comunidades quilombolas remanescentes.

Carle contemplou três quilombos - o abrigo Monjolo, em Santo Antônio da Patrulha, do século XVIII, o da Ilha do Quilombo, em Porto Alegre, do início do século XIX, e o do Paredão, do final do século XIX, em Taquara - e descreveu cerâmicas artesanais e louças localizadas nesses sítios, analisando os possíveis critérios de seleção desses locais com base em referenciais cosmológicos africanos, relacionados sobretudo com o culto dos orixás de base iorubá.

Santana, em seu estudo sobre o Quilombo do Mussuca, em Laranjeiras, Sergipe, discutiu a rejeição da memória da escravidão por parte da comunidade remanescente. A autora notou, contudo, que a paisagem cultural envolvente era marcada pela memória da escravidão, expressa

\footnotetext{
75 Pedro Funari, "Etnicidad, identidad”; Scott Allen, “A ‘Cultural Mosaic' at Palmares? Grappling with Historical Archaeology of a Seventeenth-Century Brazilian Quilombo", in Pedro Funari (org.), Cultura material e arqueologia histórica (Campinas: Unicamp, 1998), pp. 141-78.

${ }^{76}$ Charles Orser, A Historical Archaeology of the Modern World, New York: Plenum, 1996.

77 Michael Rowlands, "Black Identity and a Sense of Past in Brazilian National Culture", in Pedro Funari, Sian Jones e Martin Hall (orgs.), Back from the Edge-Archaeology in History (London: Routledge, 1999), pp. 142-64.

78 Scott Allen, "Identidades em jogo: negros, índios e a arqueologia da Serra da Barriga", in L. de Almeida, M. Galindo e J. Elias (orgs.), Índios do Nordeste: temas e problemas 2 (Maceió: EDUFAL, $2000)$ pp. 245-75; Scott Allen, “As vozes do passado e do presente: arqueologia, política cultural e o público na Serra da Barriga”, Clio, Série Arqueológica, v. 20, n. 1 (2006), pp. 81-101.

79 Allen, "As vozes do passado, p. 98.

80 Cláudio Carle, "A organização espacial dos assentamentos de ocupação tradicional de africanos e descendentes no Rio Grande do Sul, nos séculos XVIII e XIX” (Tese de Doutorado, Pontifícia Universidade Católica do Rio Grande do Sul, 2005).
} 
nas ruínas de engenhos de açúcar oitocentistas, nos caminhos, nas casas e em outros lugares de significância para a comunidade, como a várzea e a pedreira. ${ }^{81}$ Dentre as manifestações culturais, destacou a festa do Lambe-Sujo, uma possível representação de batalhas entre negros e índios, na qual a ancestralidade escrava é rememorada.

Symanski e Zanettini abordaram o processo de etnogênese da população afrodescendente que, desde o século XVIII, habita o Vale do Guaporé, em Mato Grosso e Rondônia, ${ }^{82}$ região que foi abandonada pela elite luso-brasileira no começo do século XIX. O complexo material relacionado com o processo de colonização foi reapropriado pela população africana e afrodescendente composta, sobretudo, por forros e quilombolas. Esses grupos conformaram, assim, um território afrodescendente que se estendeu por todo o Vale do Guaporé, tendo como centro o núcleo urbano de Vila Bela, e construíram simultaneamente uma identidade própria, fortemente pautada em referenciais culturais centro-africanos. Entrevistas realizadas em comunidades quilombolas, o registro de assentamentos abandonados e pesquisas em fontes primárias e secundárias permitiram um entendimento do processo de construção da territorialidade afro-guaporeana desde a primeira metade do século XVIII até o período atual, marcado pela intensa desconfiguração social decorrente da expansão dos grandes latifúndios, produto das políticas de exploração econômica da Amazônia a partir dos anos 1960.

Carvalho abordou o papel das árvores e herbáceas no espaço do Quilombo do Boqueirão, em Vila Bela, Mato Grosso, como artifícios mnemônicos referentes às crenças e culturas dos antepassados da comunidade atual ${ }^{83} \mathrm{~A}$ autora discorreu sobre a localização de determinadas plantas em relação ao espaço doméstico - herbáceas plantadas no entorno das casas com o intuito de proteção, a exemplo da espada-de-

81 Regina Norma de Azevedo Santana, "Mussuca: por uma arqueologia de um território negro em Sergipe D’El Rey” (Dissertação de Mestrado, Universidade Federal do Rio de Janeiro, 2008).

82 Luís C. P. Symanski e Paulo Zanettini, "Encontros culturais e etnogênese: o caso das comunidades afro-brasileiras do Vale do Guaporé", Vestígios, Revista Latino-Americana de Arqueologia Histórica, v. 4, n. 2 (2010), pp. 89-123.

83 Patrícia Marinho de Carvalho, "A travessia atlântica de árvores sagradas: estudos de paisagem e arqueologia em área de remanescente de quilombo em Vila Bela/MT” (Dissertação de Mestrado, Universidade de São Paulo, 2012). 
-são-jorge, comigo-ninguém-pode, guiné e dracena vermelha, e árvores como a mangueira e o pinhão branco - e constatou que essas plantas são empregadas em terreiros de candomblé de São Paulo e do Mato Grosso, estando associadas a determinados orixás do panteão iorubá, bem como a certas divindades centro-africanas, cultuadas por grupos bantos.

Guaraldo estudou os assentamentos da comunidade quilombola dos Mandira, no município de Cananeia, São Paulo, discutindo o processo de formação desse território e as formas como as paisagens e sítios históricos são apropriados como marcadores da identidade desse grupo ${ }^{84}$

\section{A arqueologia de senzalas}

As pesquisas arqueológicas em senzalas foram iniciadas somente na década de 1990, quando Lima, Bruno e Fonseca escavaram a Fazenda São Fernando, em Vassouras, Rio de Janeiro, relacionada com o ciclo do café ${ }^{85}$ Em sintonia com os trabalhos de orientação marxista norte-americanos da época, a meta dos autores foi resgatar elementos materiais do cotidiano dos cativos para investigar as práticas socioculturais que teriam desenvolvido sob a opressão, mas recuperaram basicamente materiais construtivos. A escassez de itens relacionados com as práticas cotidianas, representados apenas por poucos fragmentos de louças e vidros, levou os autores a considerar duas hipóteses:

[...] ou o sistema de controle sobre a escravaria na Fazenda São Fernando era de tal forma rígido, que aos negros era vedado qualquer tipo de tralha pessoal ou doméstica, ou, com a abolição, foram eliminados todos os testemunhos da escravidão, o que explicaria a evidência negativa ${ }^{86}$

Pesquisas mais recentes incluem uma senzala urbana em Martinho da Serra, Rio Grande do Sul, ${ }^{87}$ senzalas de dois engenhos de açúcar da

\footnotetext{
84 Fábio Guaraldo, "Terra de quilombo: arqueologia da resistência e etnoarqueologia no território Mandira, município de Cananeia/SP”. (Dissertação de Mestrado, Universidade de São Paulo, 2012).

85 Tânia Andrade Lima, M. Bruno e M. Fonseca, "Sintomas do modo de vida burguês no Vale do Paraíba, século XIX: a Fazenda São Fernando, Vassouras, RJ”, Anais do Museu Paulista, História e Cultura Material, Nova Série, n. 1 (1993), pp.170-206.

86 Lima, Bruno e Fonseca, "Sintomas", p. 187.

87 N. Machado e S. Milder, "Negros e coronéis na região central do Rio Grande do Sul - um estudo de caso: o casarão dos Mello, Martinho da Serra”, Anais do Terceiro Encontro de Pós-Graduação da Universidade do Vale do Paraíba, Universidade do Vale do Paraíba. CD-ROM.
} 
Chapada dos Guimarães, Mato Grosso, ${ }^{88}$ e as senzalas do Engenho São Joaquim, em Pirenópolis, Goiás. ${ }^{89}$

As pesquisas nos engenhos da Chapada dos Guimarães e de São Joaquim revelaram uma significativa amostra da vida material dos grupos escravizados que ocuparam esses sítios nos séculos XVIII e XIX, destacando-se vasilhames cerâmicos, louças europeias de baixo valor econômico, garrafas e ornamentos como contas de colar de vidro, pulseiras e brincos de cobre.

As senzalas do Engenho São Joaquim foram abordadas por Souza como espaços de alteridade em relação à sociedade dominante. ${ }^{90}$ Uma estrutura de fogueira, ossos de mamíferos, fragmentos de cerâmica, louças, vidros, balas, pederneiras, isqueiros e vidros lascados são vestígios que deixam perceber como os cativos transformaram esses cubículos em espaços complexos, em que desenvolveram um conjunto diversificado de estratégias cotidianas, tais como formas específicas de socialização, hábitos alimentares diferenciados, manutenção de uma economia informal e minimização de suas limitações materiais a partir da produção artesanal e da reciclagem. Para o autor, o processo de transformação cultural dos grupos escravizados do Engenho São Joaquim teria possibilitado a formação de um conjunto coerente de referências nas senzalas, "permitindo que as vivências fossem constantemente recriadas e reinventadas ao longo de gerações". ${ }^{91}$

Mais recentemente, Symanski realizou escavações no Colégio dos Jesuítas de Campos dos Goytacazes, Rio de Janeiro, identificando uma ampla área de deposição de refugo que remonta à primeira metade do século XIX, na extremidade noroeste do amplo conjunto de senzalas em

88 Symanski, "Slaves and Planters"; Luis Symanski e Marcos A. Souza, "A arqueologia histórica: relações sociais e construção de identidades na região do Rio Manso, séculos XVIII e XIX", in Leila Fraga (org.), História e Antropologia no Vale do Rio Manso (Goiânia: Editora UCG, 2006), pp. 241-64

89 Marcos Souza, "Uma outra escravidão: a paisagem social do Engenho de São Joaquim, Goiás", Vestígios, Revista Latino-Americana de Arqueologia Histórica, v. 1, n. 1 (2007), pp. 57-88; Marcos Souza, "Spaces of Difference: an Archaeology of Slavery and Slave Life in a 19th Century Brazilian Plantation" (Tese de Doutorado, Syracuse University, 2010); e Souza, "A vida escrava",

90 Souza, "Spaces of Difference".

91 Souza, "A vida escrava"; Marcos Souza, Spaces of Difference: an Archaeology of Slavery and Slave Life in a 19th Century Brazilian Plantation, Jackson: University Press of Mississippi, no prelo. 
forma de U que envolvia a sede do Colégio. ${ }^{92}$ A escavação revelou uma estrutura de fogueira e uma grande quantidade de ossos de mamíferos domésticos e silvestres, conchas de mariscos, fragmentos de cerâmicas, louças portuguesas do século XVIII e inglesas do século XIX, ornamentos de cobre martelado, contas de colares de vidro e cachimbos de cerâmica.

Por fim, devem ser citadas as pesquisas de Medeiros na Fazenda São Bento de Jaguaribe, Pernambuco, com escavações em uma provável senzala, funcionalidade essa questionada, porém, pela autora diante do conteúdo material encontrado - fragmentos de louça, grés e vidro, cerâmicas, botões, moedas e uma bala - que a ela pareceu "destoar do que seria esperado em se tratando de uma senzala", ${ }^{93}$ apesar de trabalhos sobre senzalas dos Estados Unidos, do Caribe e do Brasil registrarem que tais elementos são praticamente onipresentes nesses espaços. ${ }^{94}$

\section{Estudos bioarqueológicos}

Pesquisas bioarqueológicas em remanescentes ósseos encontrados em cemitérios de cativos são recentes no Brasil.

Silva analisou a arcada dentária de 55 esqueletos de africanos sepultados na antiga Catedral da Sé de Salvador (1553 a 1933), com o fim de estudar as condições de saúde bucal e determinados hábitos culturais desses indivíduos. ${ }^{95}$ Segundo ele, a série esquelética examinada seria procedente da Costa da Mina, datando predominantemente do século XIX. Alguns esqueletos apresentavam mutilações dentárias intencionais, principalmente dos dentes incisivos, prática essa bastante comum a diversas populações do globo, mas o autor destacou que, somente após o

92 Luis C. P. Symanski, "Projeto Café com Açúcar: arqueologia da escravidão em uma perspectiva comparativa no sudeste rural escravista - séculos XVIII e XIX”. Projeto financiado pelo CNPq. Luis C. P. Symanski e Flávio Gomes, "Arqueologia da escravidão em fazendas jesuítas: primeiras notícias da pesquisa”, História, Ciências, Saúde - Manguinhos, v.19 (2012), pp. 309-17.

93 Mércia Medeiros, "Reconstituição de uma fazenda colonial: estudo de caso, Fazenda São Bento de Jaguaribe" (Dissertação de Mestrado, Universidade Federal de Pernambuco, 2005), p. 86.

94 Para os contextos brasileiros, uma revisão geral da cultura material em sítios de ocupação africana e afro-descendente é apresentada em Luis Symanski e Marcos A. Souza, "O registro arqueológico dos grupos escravizados: questões de visibilidade e preservação”, Revista do Patrimônio Histórico e Artístico Nacional, n. 33 (2007), pp. 215-44.

95 Andersen Líryo da Silva, "Saúde bucal dos escravos da Sé de Salvador", Rede-A, v. 1, n. 1 (2011), pp. 19-43. 
contato com os africanos, alguns povos indígenas brasileiros começaram a mutilar os dentes. Ele verificou ainda uma baixa incidência de cáries, abscessos e perdas dentárias em vida nessa população, o que atribuiu a um baixo consumo de açúcar e de carboidratos.

Em amostras do esmalte dentário de 30 indivíduos sepultados no Cemitério dos Pretos Novos (1769 a 1830), zona portuária do Rio de Janeiro, Bastos e sua equipe realizaram análises de isótopos de estrôncio - assinaturas geoquímicas ligadas às características das rochas de uma região que permitem depreender a origem geográfica de indivíduos, tendo em vista que os dentes são formados na infância. Naquele cemitério, foram sepultados dezenas de milhares de escravos, sobretudo recém-chegados da África, ${ }^{96} \mathrm{e}$ a ampla diversidade de valores da análise sugeriu origens bastante diversificadas para tais indivíduos, conclusões que poderão ser refinadas à medida que se obtenham informações detalhadas sobre a geologia do continente africano. A maioria dos exemplares exibia sinais de polimento do esmalte, em coincidência com práticas de higiene bucal africanas, baseadas na mastigação de determinadas folhas e gravetos de plantas, práticas que foram abandonadas após seu translado para a América ${ }^{97}$ Como no caso da Sé de Salvador, foram também identificadas mutilações em dentes incisivos de diversos indivíduos.

\section{Artefatos, identidades e trocas culturais}

Alguns estudos têm se ocupado de classes específicas de artefatos associadas aos grupos escravizados, tais como cerâmicas, ${ }^{98}$ cachim-

\footnotetext{
96 Murilo Bastos et alii, "Da África ao Cemitério dos Pretos Novos, Rio de Janeiro: um estudo sobre as origens de escravos a partir da análise de isótopos de estrôncio no esmalte dentário", Revista de Arqueologia, v. 24, n. 1 (2011), pp. 66-81.

97 Sheila M. de Souza, Della Cook, Murilo Bastos, Ricardo Santos, "Cemitério dos Pretos Novos: Técnicas modernas ajudam a compreender questões da escravidão", Ciência Hoje, v. 49, n. 241 (2012), pp. 22-7.

98 Ver Ondemar Dias Jr., “A cerâmica neo-brasileira”, Arqueo-IAB - Textos Avulsos, v.1 (1988), pp. 3-13; André Jacobus, "Louças e cerâmicas no sul do Brasil no século XVIII: o registro de Viamão como estudo de caso", Revista do CEPA, v. 20 (1996), pp. 7-58; Camilla Agostini, "Padrões de decoração em vasilhames cerâmicos do Rio de Janeiro, século XIX”, Revista de Arqueologia, v. 11 (1998), pp. 15-26. Allen, "A 'cultural mosaic"; Gislaine Lima e Hellen Carvalho, A cerâmica de Vila Boa de Goiás dos séculos XVIII e XIX. Goiânia: Sebrae, 2004; Walter Morales, "A cerâmica 'neo-brasileira' nas terras paulistas: um estudo sobre as possibilidades de identificação cultural através dos vestígios materiais na vila de Jundiaí do século XVIII", Revista do Museu de Arqueologia e Etnologia, v. 11
} 
bos, ${ }^{99}$ vidros lascados, ${ }^{100}$ contas de colar ${ }^{101}$ e sapatos, ${ }^{102}$ encontrados em unidades domésticas, engenhos, povoados de mineração, quilombos, cemitérios urbanos e lixeiras coletivas.

Um importante desdobramento de tais estudos diz respeito ao repensar os conceitos tradicionais da arqueologia histórica brasileira, particularmente o de tradição neobrasileira. Inicialmente definida como uma "tradição cultural caracterizada pela cerâmica confeccionada por grupos familiares, neobrasileiros ou caboclos, para uso doméstico, com técnicas indígenas e de outras procedências", ${ }^{103}$ explicitou-se, posteriormente, a influência de africanos, sobretudo nos vasilhames cerâmicos com decoração incisa. ${ }^{104}$

Estudos recentes têm, contudo, refutado esse conceito, vez que as variações regionais não explicam a variabilidade presente em diferentes sítios em uma mesma região.

Morales, ao estudar cerâmicas coloniais de Jundiaí, São Paulo,

(2001), pp. 165-88; Marcos A. Souza, "Entre práticas e discursos: a construção social do espaço no contexto de Goiás do século XVIII", in Andrés Zarankin e Maria Senatore (orgs.), Arqueologia da sociedade moderna na América do Sul: cultura material, discursos e práticas (Buenos Ayres: Tridente, 2002), pp. 63-86; Marcos A. Souza e Luis Symanski, "Slave Communities and Pottery Variability in Western Brazil”, International Journal of Historical Archaeology, v. 13 (2009), pp. 513-48; Camilla Agostini, "Panelas e paneleiras de São Sebastião: um núcleo produtor e a dinâmica social e simbólica de sua produção nos séculos XIX e XX”, Vestígios, v. 4, n. 2 (2010), pp. 1-20; Marcos A. Souza e Camilla Agostini, "Body Marks, Pots and Pipes: Some Correlations between African Scarifications and Pottery Decoration in Eighteenth and Nineteenth-Century Brazil", Historical Archaeology, v. 46, n. 3 (2012); Luís Symanski, "Cerâmicas, identidades escravas e crioulização nos engenhos de Chapada dos Guimarães (MT)", História Unisinos, v. 14, n. 3 (2010), pp. 294-310; Paulo Zanettini, "Maloqueiros e seus palácios de barro: o cotidiano doméstico na casa bandeirista" (Tese de Doutorado, Universidade de São Paulo, 2005).

99 Ver Camilla Agostini, "Resistência cultural e reconstrução de identidades: um olhar sobre a cultura material de escravos do século XIX", Revista de História Regional, v. 3, n. 2 (1998), pp. 115-37.

${ }_{100}$ Ver Luis Symanski e Sérgio Osório, "Artefatos reciclados em sítios históricos de Porto Alegre", Revista de Arqueologia, v. 9 (1996), pp. 43-54. Souza, "Spaces of Difference”, pp. 200-2.

${ }^{101}$ Ver Áurea Tavares, "Vestígios materiais nos enterramentos na antiga Sé de Salvador: postura das instituições religiosas africanas frente à Igreja Católica em Salvador no período escravista" (Dissertação de Mestrado, Universidade Federal de Pernambuco, 2006).

102 Ver Tânia A. Lima, "Los zapateros descalzos: arqueología de una humillación en Rio de Janeiro del siglo XIX”, in Félix Acuto e Andrés Zarankin (orgs.), Sed non satiata II: acercamientos sociales en la arqueologia latinoamericana (Buenos Aires: Encuentro, 2008), pp. 33-55.

${ }^{103}$ Igor Chmyz, "Terminologia arqueológica brasileira para a cerâmica", Cadernos de Arqueologia, v. 1 , n. 1 (1976), p. 130.

${ }^{104}$ Dias Jr., “A cerâmica”, p. 3-13.

190 Afro-Ásia, 49 (2014), 159-198 
chamou a atenção para a grande diversidade do material de contextos domésticos que se caracterizam pela diversidade cultural, sob influências indígenas, africanas e europeias, em contraste com a produção para a venda nos aldeamentos indígenas. Segundo o autor, ambos os tipos de produção coexistiram e podem ser encontrados no mesmo sítio. ${ }^{105} \mathrm{Jaco}-$ bus também reconheceu que a produção dessas cerâmicas para comércio pode ter sido mais ampla do que tradicionalmente aceita, apontando uma possível influência de grupos bantos da África Central sobre uma parcela significativa desse material no sul do Brasil ${ }^{106}$ e Agostini destacou as possibilidades de variação de acordo com contextos urbanos, semirrurais e rurais do estado do Rio de Janeiro. ${ }^{107}$

Mais recentemente, Zanettini, reconhecendo que ainda há uma insuficiência de informações que permitam selecionar com clareza zonas de produção, redes de distribuição, troca e comercialização, propôs a substituição do termo "cerâmica neobrasileira" por "cerâmica de produção local-regional" e enfatizou os processos de transculturação que envolveram negociação, resistência e reformulação de identidades em relação a essa categoria material no contexto da sociedade paulista colonial. ${ }^{108}$ Para Souza, o conceito de tradição neobrasileira serviu mais para homogeneizar do que para revelar a diversidade cultural expressa por esse material. Segundo ele, o conceito resultou na essencialização dessa categoria cerâmica em termos de noções preconcebidas de cultura e identidade nacional, dada sua associação com sincretismos, sínteses e mosaicos culturais. ${ }^{109}$

$\mathrm{Na}$ maioria desses estudos, o processo de trocas culturais entre africanos, ameríndios e europeus tem sido abordado com base em modelos alternativos ao paradigma da aculturação, tradicionalmente utilizado para explicar as mudanças no comportamento material das populações indígenas, sobretudo em reduções e aldeamentos. A ênfase tem recaído nos modelos de crioulização, transculturação e etnogênese. Embora não sejam correlatos, tais modelos buscam entender como as

\footnotetext{
${ }^{105}$ Morales, "A cerâmica "neo-brasileira"”, p. 184.

106 Jacobus, "Louças e cerâmicas", p. 49.

107 Agostini, "Padrões de decoração", p. 15.

108 Zanettini, "Maloqueiros e seus palácios", p. 249.

${ }_{109}$ Marcos A. Souza, "Esencializando las cerámicas: culturas nacionales y prácticas arqueológicas en América", in Acuto e Zarankin (orgs.), Sed non Satiata II, pp. 141-55.
} 
trocas entre grupos e sociedades distintas levam à emergência de novas configurações culturais.

Estudos de Allen e de Funari discutiram o processo de etnogênese em Palmares, Alagoas. Allen criticou o modelo de mosaico cultural estático, tradicionalmente empregado para explicar a sociedade de Palmares, substituindo-o pela noção de sincretismo, que enfatiza a fusão de elementos culturais de várias fontes simbolicamente renegociados no novo contexto. Propôs, assim, que a identidade palmarina teria sido forjada em um cenário pluralístico que englobava africanos, indígenas e europeus, como uma resposta às interações dessa comunidade com a sociedade colonial envolvente. ${ }^{110}$ Funari, por sua vez, criticando os modelos que têm tratado a identidade étnica como uma dimensão estática, que pode ser diretamente correlacionada com a cultura material, adotou, em seu lugar, um modelo multidimensional que considera a etnicidade como diferentemente constituída em diferentes domínios. Segundo ele, indicadores estáticos de etnicidade, como os nomes africanos e os topônimos indígenas, apontados pelos cronistas da época como caracterizadores do Quilombo dos Palmares e de algumas facetas de sua organização social não podem servir para explicar a identidade de Palmares, por ter resultado aquela sociedade de contatos entre povos e tradições diversas. ${ }^{111}$

Souza, em seu estudo sobre o arraial de mineração colonial de Ouro Fino, Goiás, analisou as maneiras como uma população composta de europeus, africanos e brasileiros de diversas regiões da colônia utilizou as cerâmicas de produção local e regional para construir um senso de identidade regional forjado em uma visão de mundo barroca. $\mathrm{O}$ autor verificou uma forte correlação entre determinadas morfologias cerâmicas e padrões decorativos, com as panelas contendo decorações incisas de influência africana e as tigelas decorações pintadas similares àquelas das louças portuguesas. Para ele, essas diferenças expressariam relações assimétricas como gênero e etnicidade. Desse modo, apesar de uma visão de mundo barroca incorporada pela população em geral, a cultura material cotidiana teria sido utilizada para sustentar as desigualdades desses grupos. ${ }^{12}$

\footnotetext{
${ }^{110}$ Allen, "A 'cultural mosaic"”.

111 Funari, "Etnicidad, identidad", pp. 77-96.

112 Souza, "Entre práticas e discursos".
} 
Souza e Symanski estudaram a variabilidade diacrônica da cerâmica de três engenhos e um quilombo de Chapada dos Guimarães, Mato Grosso, ocupados entre 1780 e 1888, visando a discutir o papel desse material na emergência e na transformação de comunidades escravizadas nessa região. ${ }^{113} \mathrm{~A}$ forte correspondência entre as mudanças diacrônicas nas técnicas e nos padrões de decoração da cerâmica e as mudanças na composição africana na região indicariam que a cerâmica teria sido utilizada para expressar diferenças culturais e sociais. Quando, porém, o cenário demográfico da escravidão na Chapada dos Guimarães foi dominado, a partir do último terço do século XIX, por uma população afrodescendente, houve uma gradual diminuição na proporção dos vasilhames cerâmicos decorados, revelando que o processo cultural de crioulização nessa região teria sido fortemente atrelado às mudanças geracionais nas senzalas, de uma população heterogênea africana para uma população afrodescendente, culturalmente mais homogênea. Esse estudo sugeriu que o processo de crioulização não segue uma via linear, em que grupos com diferentes backgrounds culturais rapidamente constroem uma nova cultura como resposta à vida comum em cativeiro, devendo, porém, ser contextualmente avaliado, pois pode apresentar ritmos distintos de acordo com as especificidades da escravidão em diferentes regiões das Américas, podendo, como no caso em exame, ser marcado por períodos de expressão de diferenças e reconstrução de identidades pautadas em referenciais diversificados.

Agostini examinou o núcleo produtor de cerâmicas de São Sebastião, no litoral norte de São Paulo, onde, desde o século XVIII, vigorou uma produção doméstica de vasilhames destinada ao comércio. A autora observou que, apesar de muitos desses vasilhames terem sido decorados com motivos que remetem aos africanos, não foram eles os produtores dessas peças mas a população caiçara local, o que leva a questionar-se se africanos teriam influenciado sua estética. Tais evidências sugerem que teria havido mais do que apenas

[...] um interesse africano em consumir insígnias com significados particulares para eles, mas também um senso comum de que utensílios de

${ }^{113}$ Symanski, "Slaves and Planters”, pp. 222-6; ver, também, Souza e Symanski, “Slaves Communities”. 
cozinha poderiam — ou deveriam — servir como suporte de uma estética cujo referencial era africano, reinterpretada na diáspora, no caso de São Sebastião, pela população caiçara. ${ }^{114}$

Outros estudos têm analisado a reprodução das escarificações de grupos africanos em cerâmicas e sua significância para esses grupos.

Nos engenhos de Chapada dos Guimarães, Mato Grosso, Symanski detectou cerâmicas com motivos decorativos similares às escarificações típicas dos africanos das principais nações que viveram na região, como minas, benguelas e moçambiques. ${ }^{115}$ Essas peças indicariam a manutenção de uma cosmologia amplamente dispersa entre os povos da África subsaariana, os quais, por considerarem que os seres humanos se originaram de vasilhames cerâmicos, tendem a antropomorfizar esses objetos, dispensando-lhes os mesmos tratamentos que dão ao corpo humano.

Souza e Agostini, ${ }^{116}$ examinando sinais associados aos grupos iorubá da Nigéria e macua de Moçambique, presentes em cerâmicas e cachimbos de diferentes regiões do Brasil, sobretudo Goiás, Mato Grosso e Rio de Janeiro, concluíram que a reprodução desses sinais teria servido de veículo para esses grupos estabeleceram novos mecanismos de coexistência.

\section{Práticas rituais e religiosidade}

Alguns estudos têm ainda apontado possíveis evidências de práticas religiosas entre grupos escravizados.

Tavares considerou que os colares encontrados em enterramentos coloniais e oitocentistas da Sé de Salvador, formados por contas de vidro, de marfim e de búzios, seriam vinculados a sistemas de crenças relacionados principalmente com o culto dos orixás pela população iorubá e apontou analogias entre formas, matérias-primas e combinação de cores dessas contas com as ainda utilizadas em rituais do candomblé, que servem de nexo entre seus portadores e entidades específicas dessa religião. Com base nessas evidências, criticou o modelo do sincretismo,

\footnotetext{
114 Agostini, "Panelas e paneleiras", p. 17

115 Symanski, "Slaves and Planters".

${ }^{116}$ Souza e Agostini, "Body Marks".
} 
que defende a fusão dos sistemas religiosos africanos com a religião católica, alegando que o que ocorreu, por parte da comunidade africana, foi a manutenção de práticas religiosas paralelas, que não chegaram a se unir enquanto sistemas doutrinários. ${ }^{117}$

Souza encontrou dois itens devocionais em uma das senzalas do Engenho São Joaquim, Goiás, um fragmento de crucifixo e um cristal negro, que seriam indicativos de práticas religiosas híbridas, o primeiro deles remetendo à devoção católica, e o segundo, a práticas espirituais de origem africana que imbuíam esse tipo de objeto de poderes destinados à proteção espiritual. ${ }^{118}$

Symanski apontou evidências de possíveis práticas religiosas de origem africana nos engenhos da Chapada dos Guimarães. Na casa-grande do Engenho Rio da Casca, foram encontrados, abaixo do piso, cristais de quartzo hialino, um cristal de lustre, cachimbos e um prato de cerâmica com uma moeda de cobre em seu centro, cunhada em 1869, no canto de um dos recintos. Um grupo de três cristais de quartzo e três cachimbos, encontrados perto da porta de entrada da casa, sugeririam a prática comum à dos bantos de Angola de esconder objetos desse tipo perto da porta de entrada das casas de seus inimigos. ${ }^{119}$ Já na senzala do Engenho Água Fria, foi encontrado, em um canto, um par de garrafas, apresentando dimensões e formas similares, uma de vidro preto e outra de grés branco. ${ }^{120}$ Achados similares em senzalas da Jamaica e dos Estados Unidos têm sido considerados como garrafas de conjuro. ${ }^{121}$ Outra evidência, onipresente na região, são signos cruciformes incisos em apliques circulares presentes nos vasilhames cerâmicos. ${ }^{122}$ Os arqueólogos que trabalham em contextos afro-americanos têm associado essa representação de uma cruz dentro de um círculo com o cosmograma bacongo, como aqui já referido. ${ }^{123} \mathrm{Na}$ Cha-

\footnotetext{
117 Tavares, "Vestígios materiais".

118 Souza, "Spaces of Difference", p. 219.

${ }^{119}$ Luiz Figueira, África banto: raças e tribos de Angola, Lisboa: Oficinas Fernandes, 1938.

${ }^{120}$ Symanski, "Slaves and Planters", pp. 233-44; ver, também, Symanski, "O domínio da tática: práticas religiosas de origem africana nos engenhos de Chapada dos Guimarães (MT)", Vestígios, Revista Latino-Americana de Arqueologia Histórica, v. 1, n. 2 (2007), pp. 7-36.

${ }^{121}$ Laurie Wilkie, "Secret and Sacred: Contextualizing the Artifacts of African-American Magic and Religion", Historical Archaeology, v. 31, n. 4 (1997), pp. 81-106.

${ }^{122}$ Souza e Symanski, "Slaves Communities", pp. 538-9; Symanski, "Slaves and Planters", 174-6.

${ }^{123}$ Ferguson, Uncommon Ground; Laurie Wilkie, "Evidence of African Continuities in the Material Culture of Clifton Plantation, Bahamas", in J. Haviser (org.), African Sites in the Caribbean (Princeton:
} 
pada, peças contendo tais apliques aparecem em contextos com datação média que se inicia em 1836, numa forte correlação com o período em que a chamada nação congo, que incluía os bacongos, se tornou o grupo africano majoritário na região, a partir de $1830 .{ }^{124}$

De uma perspectiva etnoarqueológica, há o trabalho de Ribeiro sobre o patrimônio arqueológico vinculado aos terreiros de candomblé do Recôncavo Baiano. ${ }^{125}$ Seu interesse recaiu nos locais de deposição de artefatos rituais fora dos terreiros, localizados em terrenos baldios e em áreas como estradas, encruzilhadas, bosques, rios, lagoas e praias, que foram muitas vezes utilizados por várias gerações, e o autor destacou o valor significativo desses espaços, que tendem a ser desconsiderados em pesquisas arqueológicas convencionais.

Por fim, pesquisas arqueológicas em um sítio extremamente significativo para a história e memória da escravidão africana no Brasil, o Cais do Valongo, Rio de Janeiro, vêm sendo realizadas por Lima desde janeiro de 2011, dentro das obras do projeto Porto Maravilha, que pretende revitalizar a Zona Portuária do Rio de Janeiro para as Olimpíadas de 2016. O Cais do Valongo foi o porto de entrada de cerca de um milhão de africanos no período de 1811 a 1831. Entre os milhares de objetos até o momento encontrados, destacam-se cachimbos, búzios usados em práticas divinatórias, adornos de contas, brincos com a meia-lua islâmica, miçangas e pedras de assentamento de orixás. O reconhecimento do significado religioso de muitos desses objetos tem sido realizado com o auxílio de sacerdotes e especialistas na cultura e religião africanas. ${ }^{126}$

Marcus Wiener, 1999), pp. 264-75. Uma revisão da temática do cosmograma bacongo na arqueologia norte-americana é encontrada em Christopher Fennell, “Group Identity, Individual Creativity, and Symbolic Generation in a Bakongo Diaspora”, International Journal of Historical Archaeology, v. 7, n. 1 (2003), pp. 1-31.

124 Symanski, "Slaves and Planters", p. 133; Souza e Symanski, "Slaves Communities", pp. 538-9.

${ }^{125}$ Ademir Ribeiro Junior, "Patrimônio etnoarqueológico de terreiros de candomblé: tensões entre a memória coletiva e o poder hegemônico". Anais do XI Congresso Luso-Brasileiro de Ciências Sociais, Salvador, Universidade Federal da Bahia, 2011.

${ }^{126}$ Ver Guilherme Rosa, "Um tesouro arqueológico no Rio de Janeiro", entrevista com a arqueóloga Tania Andrade Lima, Galileu, <http://revistagalileu.globo.com/Revista/ Common/0,ERT225809-17770,00.html>, acessado em 24/01/2013; e Carlos Haag, “Ossos que falam: escavações na zona portuária do Rio de Janeiro revelam retrato pouco conhecido da escravidão", Pesquisa FAPESP, n. 190 (2011), pp. 24-9. 
Além de inúmeras informações sobre as condições materiais de vida dos africanos recém-chegados da África que eram comercializados em várias casas na região do Valongo, o estudo desses artefatos deverá revelar informações fundamentais sobre os sistemas de crenças e práticas rituais trazidas por esses grupos em sua entrada no Brasil, servindo de base para uma compreensão mais profunda da emergência da religiosidade afro-brasileira e, assim, dos mecanismos que regem o processo de crioulização.

\section{Considerações finais}

Conforme discutido, a arqueologia da diáspora africana nos Estados Unidos passou por intensas modificações ao longo de sua trajetória. Iniciada com trabalhos de natureza eminentemente descritiva, dentro do paradigma histórico-cultural, passou, ao longo das décadas, ao estudo dos processos de aculturação e, já sob a influência da abordagem processualista, às tentativas de reconhecimento de padrões afro-americanos. Sob a influência de abordagens marxistas, a partir da década de 1990, o foco voltou-se para a análise das relações de poder, inicialmente considerado de uma forma unidirecional, o poder da camada senhorial sobre os grupos escravizados, e posteriormente considerando tais relações como vias de mão dupla, demonstrando as estratégias de negociação social entre esses dois grupos dicotômicos. Dessa perspectiva mais balanceada, emergiram também os estudos de crioulização voltados para os processos de trocas culturais entre afro-americanos, euro-americanos e as populações ameríndias, que enfatizam a capacidade de os grupos afro-americanos se reapropriar da cultura material dos segmentos dominantes a partir de seus próprios referenciais. Mais recentemente, alguns arqueólogos começaram a dirigir a atenção para um melhor entendimento da dinâmica interna desses grupos, considerando sua capacidade de agência frente às limitações impostas pela escravidão, a partir do estudo de suas práticas cotidianas e dos mecanismos de interação social e de reprodução cultural por eles desenvolvidos.

No Brasil, apesar de os estudos arqueológicos sobre a escravidão terem se iniciado há mais de trinta anos, a arqueologia afro-brasileira ainda se encontra em seus primórdios. Não obstante, os estudos já reali- 
zados fornecem informações diversas sobre os padrões de vida material, as práticas cotidianas e os mecanismos de construção e reconstrução de identidades, sobretudo em unidades rurais. Há, porém, uma grande necessidade de ampliá-los para que possibilitem um melhor entendimento do universo material e das condições de vida dessas populações, não somente em diferentes regiões do Brasil mas também em diferentes contextos, como senzalas de unidades de produção - engenhos, fazendas de café, fazendas de gado e charqueadas - , quilombos rurais, quilombos urbanos e também unidades de habitação em contextos urbanos, ocupadas tanto por cativos quanto por africanos e afrodescendentes forros. $\mathrm{O}$ estudo desses contextos se revelará rico em informações sobre as práticas desses grupos, suas formas de autoexpressão material e as estratégias por eles desenvolvidas para interagir com - e até mesmo desafiar — a ordem social dominante.

Texto recebido em 22 de agosto de 2012 e aprovado em 15 de junho de 2013

\title{
Resumo
}

$\mathrm{O}$ artigo apresenta uma revisão dos principais temas de pesquisa abordados na arqueologia da diáspora africana nos Estados Unidos e no Brasil, adicionando, quando relevante, contextos do Caribe, com o propósito de fornecer um panorama do desenvolvimento das pesquisas nos últimos quarenta anos bem como discutir as mudanças de enfoque e de modelos teóricos aplicados para explicar a dinâmica social das populações africanas na diáspora.

Palavras-chave: arqueologia da diáspora africana - cultura material - modelos de encontros culturais - Estados Unidos - Brasil

\begin{abstract}
This article presents an overview of the main issues that have been discussed on the subject of archaeology of the African diaspora in the United States and in Brazil, adding, when pertinent, information on the contexts of the Caribbean. The goal is to furnish a wide overview on the development of the field over the last 40 years, as well as to discuss the changes in the theoretical models used to explain the social dynamics of African populations within the diaspora.
\end{abstract}

Keywords: archaeology of African diaspora - material culture - models of cultural encounters - United States - Brazil 